\title{
SEISMIC RATINGS FOR DEGRADING STRUCTURAL SYSTEMS
}

\author{
Bruce L Deam ${ }^{1}$
}

\begin{abstract}
SUMMARY
A new method has been proposed for rating the seismic resistance of degrading bracing elements used in buildings constructed to NZS 3604. Most of these bracing elements are formed from thin cladding panels nailed or screwed to light timber frames, but the rating method is also used for bracing elements constructed from other materials. A new analytical model was developed as part of this study to accurately model the load-displacement responses of these bracing elements. A continuous pseudodynamic test method was developed to assess the accuracy of the analytical model in the BRANZ structural laboratory. The analytical model accurately predicted the time-displacement responses of three, pseudo-dynamically tested, $5.4 \mathrm{~m}$ long, light timber framed wall specimens, providing confidence in its use.

The new rating method has shown that P21 rating procedure, used since 1979, was dangerously unconservative for the tested specimens. Factors that led to this discrepancy are briefly described. A simple modification to the current $\mathrm{P} 21$ rating procedure is proposed to re-rate specimens from existing test results, but this needs to be verified for a wider range of specimen responses than the three described herein.
\end{abstract}

\section{INTRODUCTION}

A significant portion of New Zealand buildings are designed and constructed using the New Zealand standard for Light Timber Framed Buildings not Requiring Specific Design, NZS 3604 [1]. This standard is predominantly used by those outside the engineering profession, so simplified design methods are used to ascertain both wind and seismic loadings. Seismic design is carried out using the fundamental structural design equation 'resistance $\geq$ demand'. The seismic bracing demand is obtained from a table of demand per square metre for specified construction styles and earthquake zones. This is multiplied by the floor or roof plan area to obtain the total demand in each of two perpendicular directions.

The resistance is provided by bracing elements within the building, which have a combined rating that matches or exceeds the demand in each direction. The bracing elements are distributed around the building in a prescribed manner in order to reduce the possibility of torsional failure. Bracing demands and ratings are both measured in Bracing Units (20 Bracing Units $\equiv 1 \mathrm{kN}$ ) so that no decimal point is needed in the calculations.

BRANZ recently completed a review [2] of the 1979 'P21' test and evaluation procedure [3] and its 1991 supplement [4] that are currently used to assess the resistance provided by bracing elements. The test and evaluation procedures used in other countries were reviewed as part of that study. Many of the procedures were variations on the reverse-cyclic P21 test procedure but there is no commonly agreed test procedure. There were no equivalent evaluation procedures. The evaluation procedures were either used to determine the ultimate strength (mostly for wind loading) or to evaluate the initial stiffness and the amount of viscous damping that is needed for time-history analysis using either elastic or elastoplastic elements.

Revised test and evaluation procedures have now been developed to provide more realistic earthquake resistance ratings. These have the following four steps:

1. Conduct a monotonic racking test with one specimen to determine its ultimate strength and ensure it is able to sustain some degree of inelastic deformation.

2. Subject three more identically constructed specimens to a reverse-cyclic racking test.

3. Fit an analytical model to the responses of these specimens and use this to determine the mass that can be restrained by the specimen for a suite of design level earthquakes.

4. Conduct a pseudo-dynamic verification test with a fifth specimen when its load-displacement response is unusual to verify that it was modelled correctly.

This paper describes the revised evaluation procedure (steps 3 and 4 above [5]) with brief reference to the test procedure (steps 1 and 2) which is detailed elsewhere [2]. The existing evaluation procedure is described first. This is followed by descriptions of an analytical model and software developed to automate the rating process (step 3). Pseudo-dynamic

\footnotetext{
'Leicester Steven EQC Earthquake Engineering Lecturer, University of Canterbury' (Member)
}

(Formerly' Structural Engineer, BRANZ) 
verification testing (step 4 ) is then described with reference to a test facility developed at BRANZ to perform these tests. The revised procedure is then compared with the current rating procedure for a set of representative elements and walls. Comments are then made on the implications of these for future revisions to NZS 3604.

\section{RATING PROCEDURES}

The current $(1979,1990)$ 'P21' method of rating the resistance of bracing elements [4] uses a reverse-cyclic test. A typical specimen response is illustrated in Figure 1. Two of the three Figure 1 resistance forces (ie R and S), are used to rate the earthquake resistance. The other, $\mathrm{P}$, is used to rate the wind resistance. All three resistances are averaged over 3 identically constructed specimens to reduce the variability of the rating. Average forces are used because most buildings are braced by several elements.

The earthquake rating is derived from the residual resistance, $\mathrm{R}$ (see Figure 1), converted to Bracing Units (1 $\mathrm{kN}=20$ Bracing Units) using the following equation [4]:

$$
\mathrm{BU}_{\mathrm{qu}}=20 \times \mathrm{K}_{4} \times \mathrm{R}
$$

where

20 converts the measured force in $\mathrm{kN}$ to Bracing Units

$\mathrm{K}_{4}$ is a ductility modification factor.

The earthquake rating is reduced when the specimen 'ductility', $\mu$, is less than $\mu=4$ which was used to derive the loads tabulated in NZS 3604:1990. The ductility was defined by the P21 method as the ratio of the maximum test displacement, $y$, to the displacement, $d$, at half of the peak load. (The reason for choosing this displacement was not described in [2]. It erroneously increases the ductility as will be described later.) The rating is also reduced to a multiple of the service resistance, $S$, when the ratio of serviceability to ultimate resistance is smaller than the ratio of serviceability to ultimate load assumed in NZS 3604. The rating is then normally divided by the specimen width, to give a rating per unit width, and rounded to the nearest 5 Bracing Units.

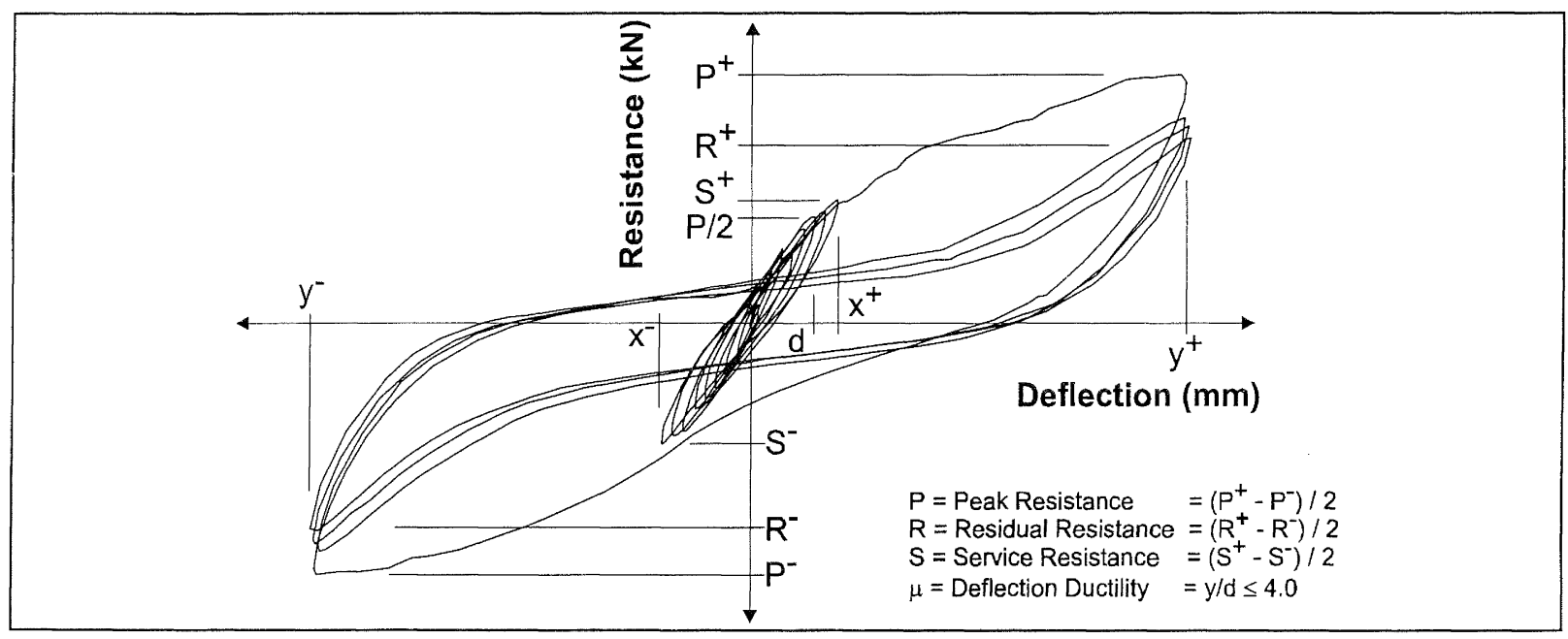

Figure 1: $\quad$ Test specimen response to the 'P21' test procedure [3].

The 'P21' test and evaluation procedures $[2,6]$ were reassessed recently after a review of test and evaluation procedures used in other countries. The test procedure was modified [4] to include an additional specimen that is used to identify undesirable brittle failure modes. A second modification includes additional cycles (between $\mathrm{x}$ and $\mathrm{y}$ in Figure 1) to provide more realistic degradation of the specimen and to allow the specimen to be rated at a smaller deflection if it fails before $y$ is reached.

A simple reverse cyclic test is used to assess brittle failure modes. It is also used to evaluate the service displacement and to ensure that the strength of the overturning restraints and other components are not likely to fail during wind loading or a large earthquake acceleration pulse. This test is only necessary when the mode of failure is not obtained from previous tests or experience. The test procedure has since been amended $[2,6]$, with additional cycles to large displacements, in order to assess the specimen response with stiff and weak restraints.
The racking test regime for step 2 was revised $[2,6]$ to both characterise the behavicur of the specimen more accurately and to make it an exploratory test. The original regime [3] required a target displacement to be estimated before the test was conducted. In practice this occasionally required a test to be repeated if the estimate was too optimistic. The test protocol is described elsewhere [6] so will not be fully described here.

The proposed evaluation method is considered to be more rigorous than the original [3], which simply rated the specimen from its resistance during the fourth cycle to the estimated displacement (see Figure 1). The proposed method is based upon that developed by Dean et al [7]. This comprised fitting an analytical model and using the model to generate displacement spectra for a number of earthquakes using single degree-of-freedom integrated time-history analysis. The mass that could be restrained by that element was then assessed from the least favourable design spectrum. Most of the process is carried out automatically using a 
computer program. The complete procedure and its accompanying computer program are described later.

The pseudo-dynamic verification test (described later) is primarily used to ensure that the analytical model characterises the test specimen sufficiently accurately. The verification is not likely to be needed once the analytical model is shown to be correct for specimens with a known range of characteristics.

\section{ANALYTICAL MODEL}

Most bracing systems degrade when subjected to reverse cyclic deformation. A number of methods have been used to fit the classic elastoplastic approximation (Figure 2b) to actual hysteresis loops of steel and concrete elements [8] since in real elements there is no distinctive point at which the onset of plastic deformation (yielding) occurs. The response of degrading elements (e.g. Figure 1) is even more poorly characterised by the elastoplastic approximation, particularly at large displacements.

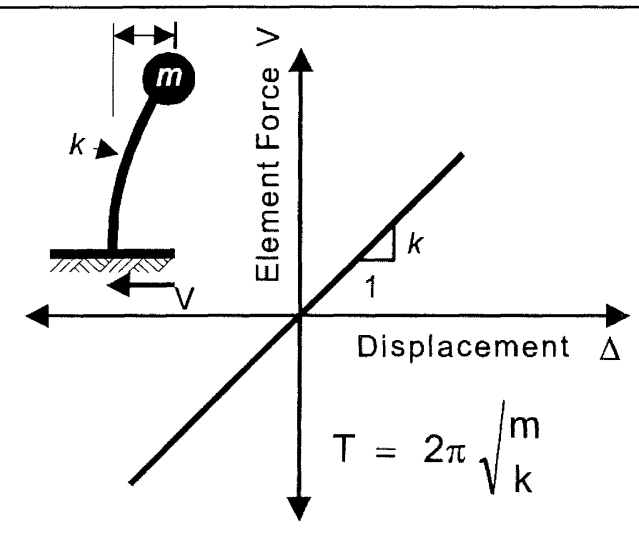

Elastic

(a)

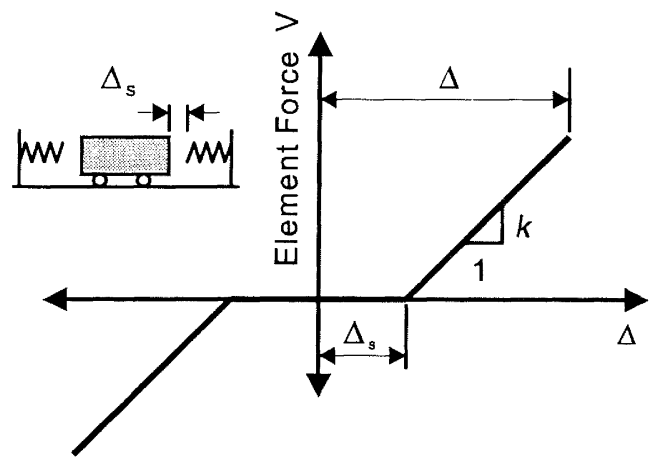

Slackness [9]

(c)

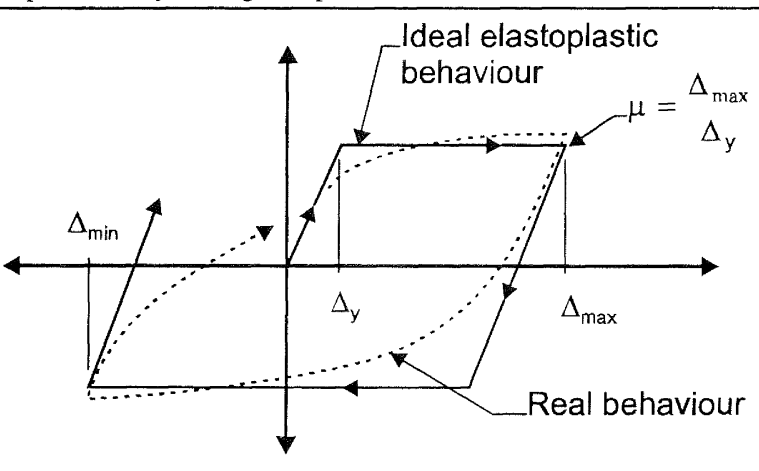

Elastoplastic [8]

(b)

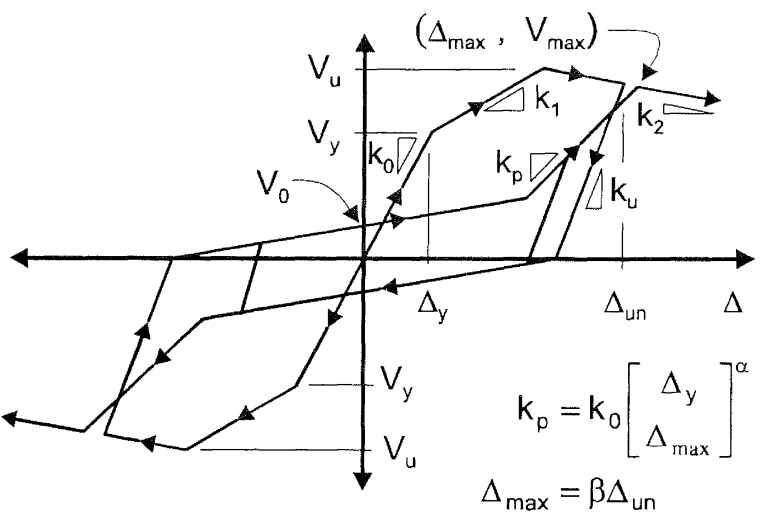

Pinched [10]

(d)

Figure 2: $\quad$ Some element hysteretic behaviour approximations.

Dean et al. [9] used a model of a mass oscillating between two linearly elastic springs (i.e. the Figure $2 \mathrm{c}$ inset) to approximate the pinched hysteresis loops of degrading elements at large displacements. This "slackness oscillator" models the element behaviour when slackness, normally present after the first major ground movement during an earthquake, is developed. However, the residual load at zero displacement is only provided by coulomb damping.

Stewart [10] developed a hysteretic model that incorporated the pinching effect observed in racking tests conducted with timber elements. This model (Figure 2d) used sets of rules to define a tri-linear approximation of the envelope of the loaddisplacement response and the pinching effects that develop during repeat loading. The model was developed for plywood shearwalls but can also represent other degrading structural elements. A number of improved rule-based methods have also been proposed, as summarised in [11], to represent the response more realistically but their major change is in the use of curves rather than straight lines.

A simpler method of generating realistic responses was developed by Dean $[12,13]$ to eliminate the need for a complex set of mathematical rules. The model used a rigid bar and a series of bi-linear elastoplastic springs (Figure 3a). It generated very realistic load-displacement responses for a range of structural sub-assemblies and timber elements, complete with smooth stiffness transitions (Figure 3e). The response was modified by altering the spring properties. Some of the springs were allowed to develop slackness (Figure 3c) as they were cycled. 


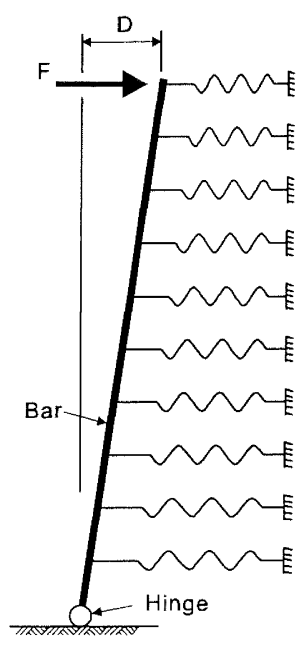

Bar and Spring Model

(a)

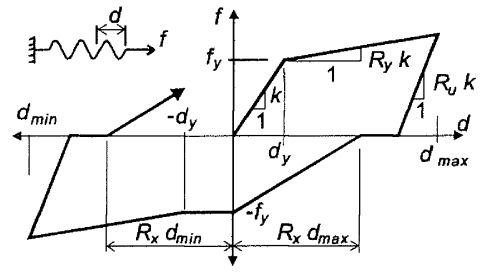

Bi-linear Spring Response

(b)

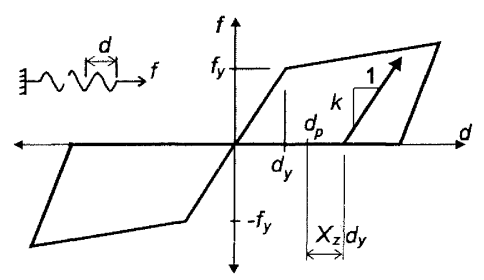

Separated Bi-linear Spring Response

(c)

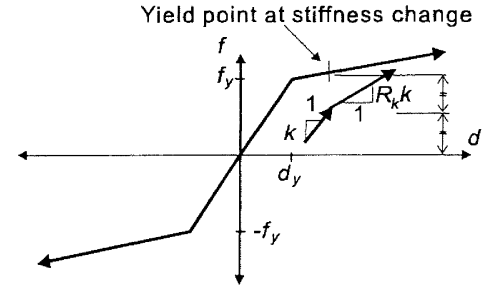

Reloading Stiffness Change

(d)

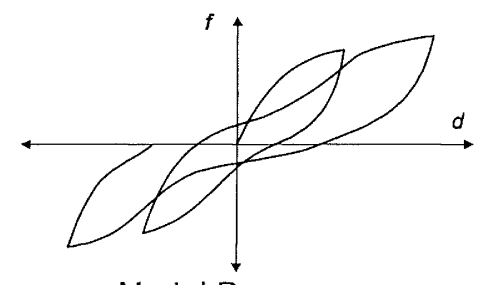

Model Response

(e)

Figure 3: Dean's bar-spring model [13].

While Dean's model [12] produced a very realistic response, the model response was only approximately related to the properties of the individual springs. The model also required a large number of calculations, which makes it unsuited to modelling other elements of a structure in a pseudo-dynamic test.

The bar and spring model was revised as part of the current study (Figure 4) to use parameters that are measurable on the load-displacement response of a test specimen. The revised (BRANZ) model uses five springs (Figure 4b) to model the embedment of a steel nail into a timber substrate. These springs develop slackness and decrease their reloading stiffness as they deform to give a more realistic response at small displacements. The nail response is approximated using a rigid bar with inelastic hinge at the base (modelled using the Fillipou-Bertero-Popov steel model [14]). The BRANZ model produces a very realistic response (Figure $2 \mathrm{c}$ ) with only seven characteristic parameters. Moreover, the parameters are directly related to the response as they were with Stewart's model (Figure 2d).

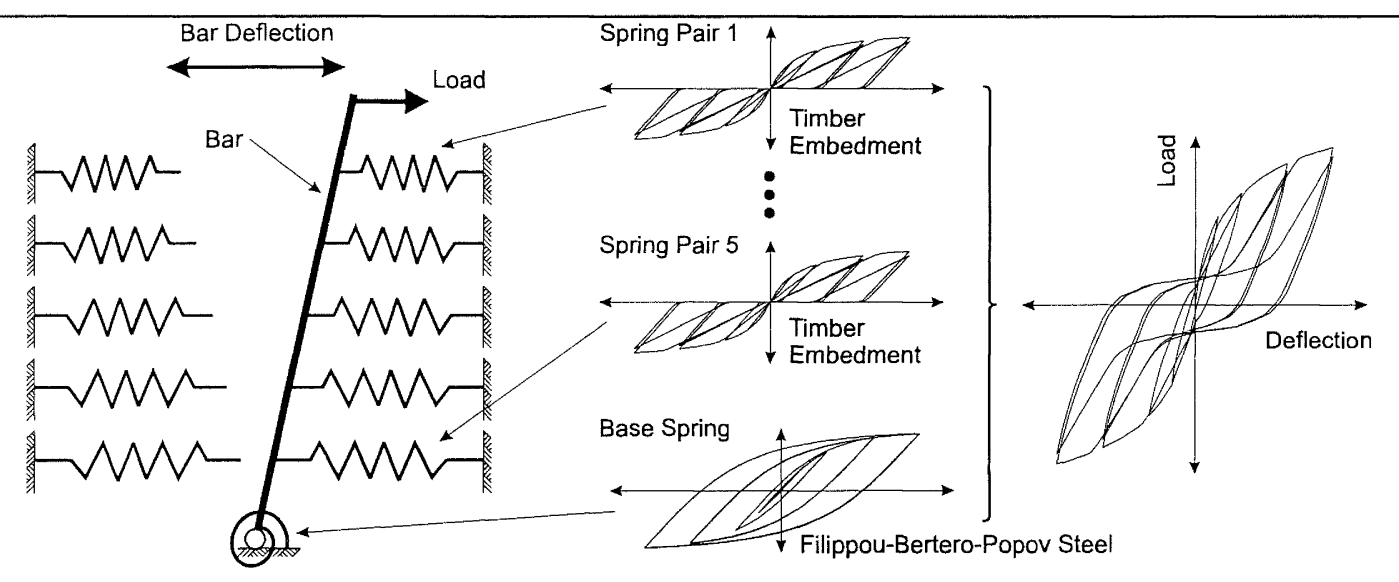

Bar-Spring Model

(a)
Spring Responses

(b)
Model Response

(c)

Figure 4: $\quad$ Revised bar-spring model. 


\subsection{Automated Rating Procedure}

Software has been developed to automate the process of characterising the test specimen responses and assessing their response to the level of earthquake ground motion specified in the NZ Loadings Standard, NZS 4203 [15]. Non-linear time-history analyses are performed within the software, named BraceRate, using acceleration records from a suite of earthquakes. Natural earthquake records were modified to generate acceleration spectra similar to the uniform risk spectrum for normal soils given in NZS 4203 [16]. The timehistory analysis is carried out for a single degree-of-freedom oscillator using the constant acceleration step-by-step method [17]. A relatively small time-step $(0.005 \mathrm{sec})$ is required for the analysis because the stiffness of the bar-spring model (Figure 4) is highly non-linear. Hysteresis loops, load-time records and displacement-time records can be plotted on the screen.

To begin the procedure, the load-displacement records for the three reverse-cyclic test specimens are loaded into the BraceRate software. The bar-spring model is then fitted to each record in turn by altering the model characteristics at the bottom of the computer screen (Figure 5) until the shapes of the test and generated responses are similar. (The strength, $\mathrm{Fu}$, has been reduced to differentiate the two responses in Figure 5. These are plotted in different colours on the computer screen.)

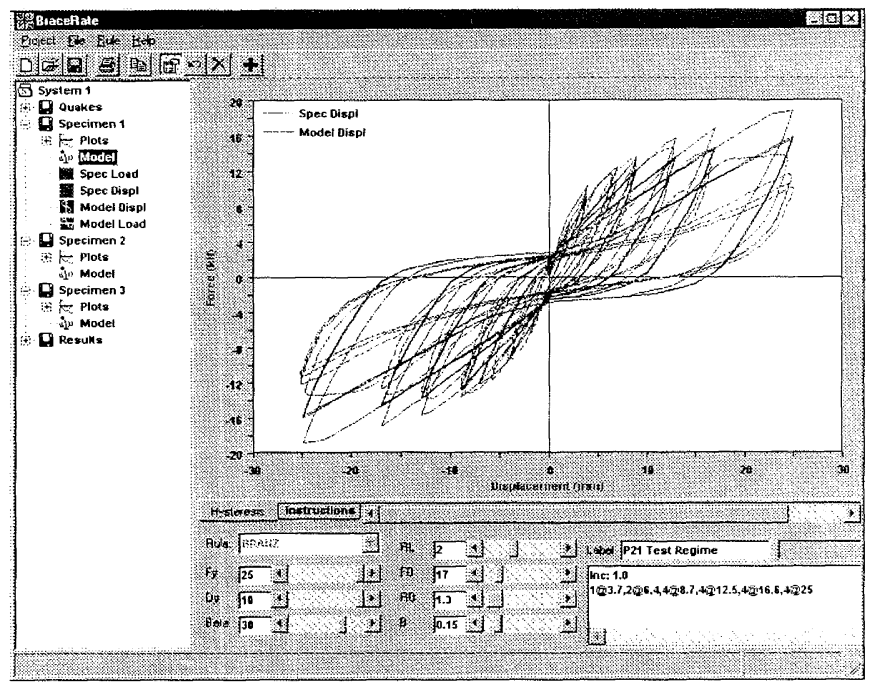

Figure 5: $\quad$ Fitting the bar-spring model to a test record using the BraceRate software.

Once the model has been fitted to each of the three specimens, a displacement spectrum is generated for each specimen subjected to each earthquake. The spectra are generated by incrementally increasing the mass in the single degree-of-freedom oscillator until the maximum displacement recorded during the time-history analysis exceeds a predefined displacement. These are plotted (Figure 6) with the displacements on the $\mathrm{x}$-axis and the mass (in place of the period) on the $y$-axis once the analysis is completed. The mass able to be restrained by the specimen is then read off the plot at the maximum reliable test displacement. Further investigation is required to establish whether the lowest or the average mass is most appropriate. BraceRate uses a suite of five earthquake accelerograms that were modified [16] so their elastic response spectra were similar to the elastic design response spectrum given in NZS 4203 for normal soils.

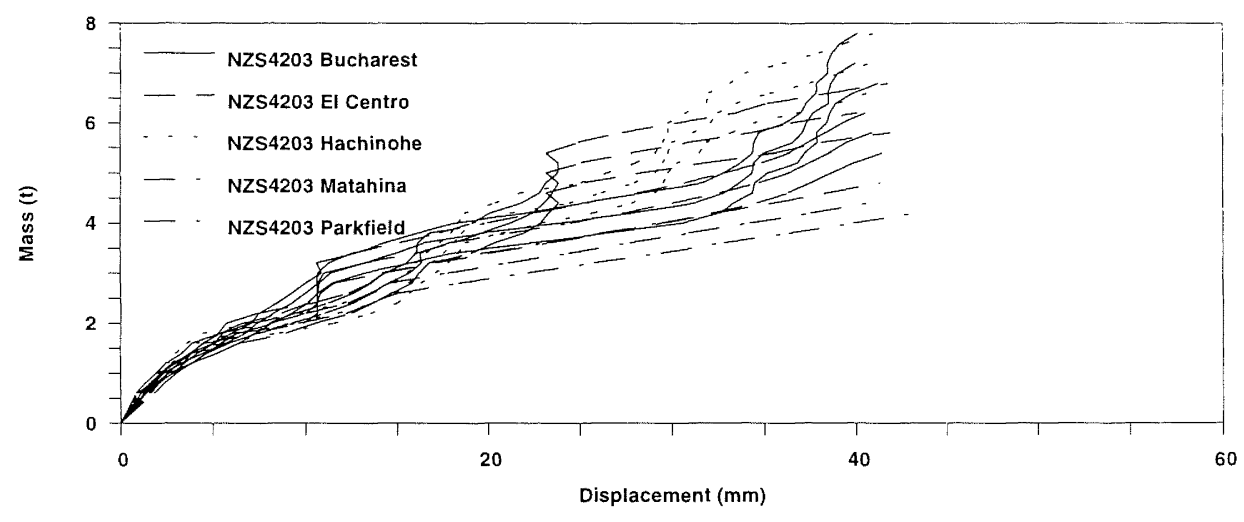

Figure 6: $\quad$ 'Displacement spectra' generated by the BraceRate software for the Figure 5 specimen. 
Earthquake design loads in NZS 3604 [1] were derived from a draft version of the loadings standard NZS 4203 [15] for a building with a period of 0.4 seconds and ductility $\mu=4$ [18]. The seismic design force, $V$, on a building of mass $M$ is given by (from equation 4.6.2 (a) of NZS 4203):

$$
\mathrm{V}=\mathrm{C}_{\mathrm{h}}(\mathrm{T}, \mu) \times \mathrm{S}_{\mathrm{p}} \times \mathrm{R} \times \mathrm{Z} \times \mathrm{L}_{\mathrm{u}} \times \mathrm{M} \times \mathrm{g}
$$

The other symbols used above are defined in equation 4.6.2 (a) of NZS 4203. Setting these to the values for NZS 3604 buildings, namely $\mathrm{R}=\mathrm{L}_{\mathrm{u}}=1, \mathrm{~S}_{\mathrm{p}}=0.67, \mathrm{~g}=9.81 \mathrm{~m} / \mathrm{sec}^{2}, \mathrm{Z}=$ 1.2 (Wellington) and $C_{h}(T, \mu)=0.27$ (for $T=0.4$ seconds, $\mu$ $=4$ and "intermediate" soil), gives:

$$
\mathrm{V}=2.13 \mathrm{M}
$$

If the seismic design force is distributed among the bracing elements in proportion to their strength rather than stiffness [19] (i.e. they are all rated at the same displacement), the building force $V$ and mass $M$ in equation 4 can be replaced by the bracing element force, $v$, and a mass, $m$, that is able to be restrained by that element. Modifying equation 4 in this manner and converting the force, $\mathrm{v}$, from $\mathrm{kN}$ to $\mathrm{BU}$ (Bracing Units) using the identity of $1 \mathrm{kN}=20 \mathrm{BU}$ as defined previously, allows the bracing rating to be calculated from the mass $m$ generated by BraceRate (i.e. from Figure 6) using:

$$
v=43 m
$$

These simplistic assumptions are adequate for investigating the differences between the original and revised rating methods. They need further investigation because buildings normally have a variety of bracing elements with differing strength and stiffness. Moreover, no account is made of the torsional response of the building.

\section{PSEUDO-DYNAMIC TESTING}

\subsection{Introduction}

Testing is acknowledged as the most accurate method of establishing how complex structural systems perform during an earthquake. Models have recently been developed [20] which accurately predict the behaviour of panel elements based upon individual fastener load-deformation responses but these are currently unable to satisfactorily predict the response of the more complex configurations used in practise. Pseudo-static reverse cyclic tests have been used for many years to assess the deformation capacity of structural systems ranging from sub-assemblages to complete buildings. Shake-table tests have been used to both observe and verify system response under more realistic conditions. On-line, computer controlled or pseudo-dynamic testing is increasingly being used in Japanese and US laboratories to simulate the inertial response of a shake-table test.

In a pseudo-dynamic test, the test specimen is used in place of a numerical model in a dynamic time history analysis. The test equipment is similar to that used for a reverse cyclic test, with the addition of an interface between the physical specimen and the numerical analysis. The pseudo-dynamic test offers several significant advantages over the physically equivalent shake table-test:

- The duration of the test may be extended to allow more detailed observation of the specimen as the test proceeds;

- The building mass is simulated which makes it simpler to vary and reduces the danger for those observing the test;

- The damping is simulated so it may be used to model damping from sources external to the specimen;

- The fidelity of the reproduction of the ground motion is improved and specimens may be physically much larger because there is no shake-table to move at the dynamic rate; and

- The specimen may be tested so that it responds as though it is within a complete structure. The remainder of the structure may be modelled analytically or even simultaneously tested in the same or another laboratory.

The pseudo-dynamic test has also has significant disadvantages:

- Only a few degrees-of-freedom can be modelled in the laboratory so it is not suitable for specimens or systems that have distributed mass (e.g. masonry facades). These specimens are often small enough to be tested on a shaketable; and

- The earthquake currently needs to be slowed down, so strain-rate effects are not modelled accurately.

In spite of the advantages over shake-table testing, the pseudo-dynamic method was not used to test timber structures [21] for more than a decade after the method was first developed [22]. This is partly because timber structures are generally regarded as being less important than those constructed from other materials. Such structures are also more difficult to test because the pseudo-dynamic test normally displaces the specimen incrementally and holds it stationary while the force measurement is recorded. Relaxation within the specimen during the stationary periods reduces the test accuracy.

The remainder of this section gives a brief description of the pseudo-dynamic test method and an adaptation of the pseudo-dynamic test developed at BRANZ to test degrading systems. The BRANZ test moves the specimen continuously throughout the test to avoid relaxation. The new method has been implemented for single test specimens and is shown to correlate very well with analytical results for linear systems.

\subsection{The Pseudo-dynamic test method}

The test rig used for a pseudo-dynamic test (Figure 7) is the same as that used for reverse cyclic testing. The racking sequence, however, is controlled by an integrated timehistory analysis as the test proceeds. It is not able to be predetermined because it is adjusted in response to changes in the applied force during the test.

The pseudo-dynamic test proceeds as a series of small steps. At each step, the test specimen (Figure $7 \mathrm{a}$ ) is racked to a calculated displacement, $\Delta_{\mathrm{A}}$, using a servo-hydraulic actuator attached to its top. The applied force $\mathrm{R}_{\mathrm{M}}$, and specimen displacement, $\Delta_{\mathrm{M}}$, are measured by a load cell and 
displacement transducer respectively. (Strains in the equipment and supports usually make $\Delta_{\mathrm{A}}$ and $\Delta_{\mathrm{M}}$ slightly different.) An analysis system (Figure $7 \mathrm{~b}$ ) integrates the earthquake acceleration record (converted to forces, $\mathrm{F}_{\mathrm{i}}$ ) and the measured load to generate an actuator displacement command for the next step. (The command, $\Delta_{\mathrm{A}}$, is modified by adding the $\Delta_{A}-\Delta_{M}$ error from the previous step.) The analysis is synchronised by a system clock.

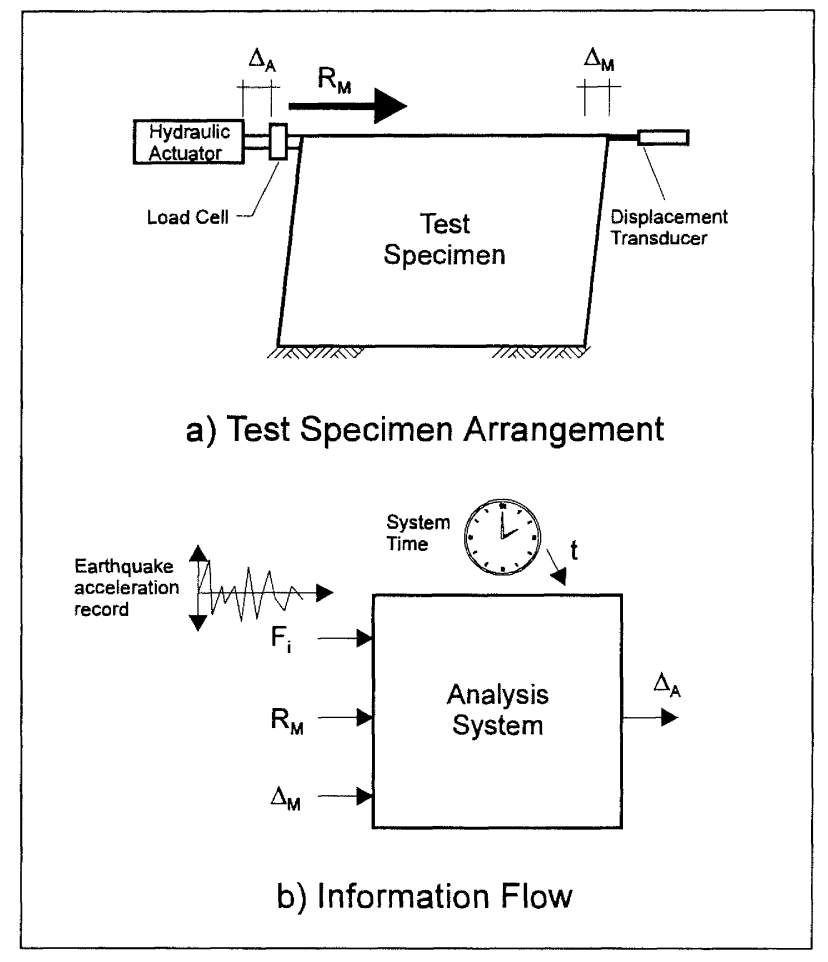

Figure 7: $\quad$ The pseudo-dynamic method.

The analysis system, the heart of the method, has been implemented in a variety of ways as the test has been developed. All of the methods are based on the solution to the classical equation of motion for a single-degree-offreedom system (Equation 5) which relates the acceleration, $\mathrm{a}$, velocity, $\mathrm{v}$, and displacement, $\mathrm{d}$, of mass $\mathrm{M}$ to the instantaneous stiffness, $\mathrm{K}$, of the element, the seismic force, $\mathrm{F}$, and a viscous damping term, $\mathrm{C}$ :

$$
\mathrm{Ma}+\mathrm{Cv}+\mathrm{Kd}=\mathrm{F}
$$

Equation 5 and its incremental equivalent are normally solved by numerical integration to obtain the velocity and displacement from the acceleration in a series of time steps. There are numerous algorithms available to perform the numerical integration, most use an explicit approach such as Newmark's method [17]. As each algorithm introduces or amplifies one or more types of error in the integration, it needs to be chosen to minimise the errors in the most important aspects.

Multiple degree-of-freedom (DOF) specimens are more difficult to test than single DOF specimens because they have several actuators attached to the same specimen. The actuators need to be operated so the new positions are attained simultaneously at each actuator. Interaction between the actuators, particularly where the specimen is very stiff [23], affects the force distribution within the specimen. One method of simplifying the multiple DOF test is to reduce it to a single DOF with a predefined load distribution - similar to a 'pushover' analysis. This form of the test is conducted by operating the actuator attached to the top of the specimen. The measured base shear force is used for the calculations [23]. Actuators attached to the lower levels are arranged to apply a portion of the force at the top.

\subsection{Specimen Relaxation}

The load drops rapidly when a timber specimen is moved and held in the new position for a period of time. The effects of relaxation are illustrated in the Figure 8 load-displacement response of a timber component tested using a hand-operated actuator. The drops in load while the pump handle is lifted are much greater than they are for steel of concrete specimens. 


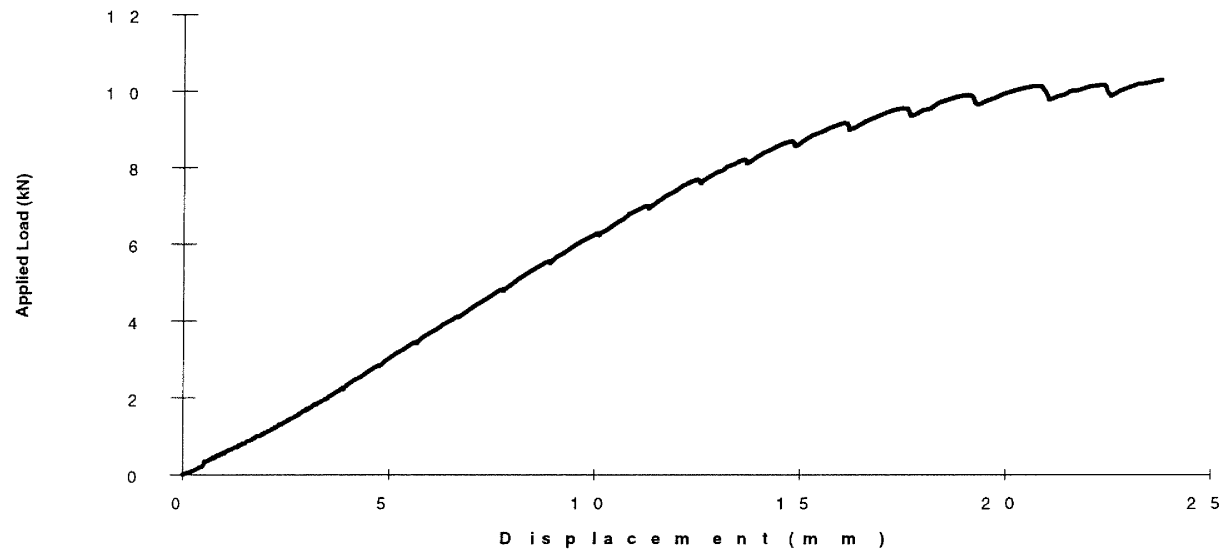

Figure 8: $\quad$ Specimen response showing relaxation.

Traditionally, pseudo-dynamic tests proceed as a sequence of ramp and hold events (Figure 9, [24]). This method introduces errors because of specimen relaxation and acceleration pulses introduced at the start and finish of each ramp. Each step in the integration of Equation 5 begins with the specimen stationary (abbreviated as 'hold') at the end of the previous step. Load and displacement measurements are acquired and used to calculate the target displacement, $d_{i+1}$, at the end of the step. The servo-actuator then moves the specimen to the target displacement at a constant velocity. (This part of the step is termed 'ramp'.) At the end of the step, the ramp is stopped and the next step begins.

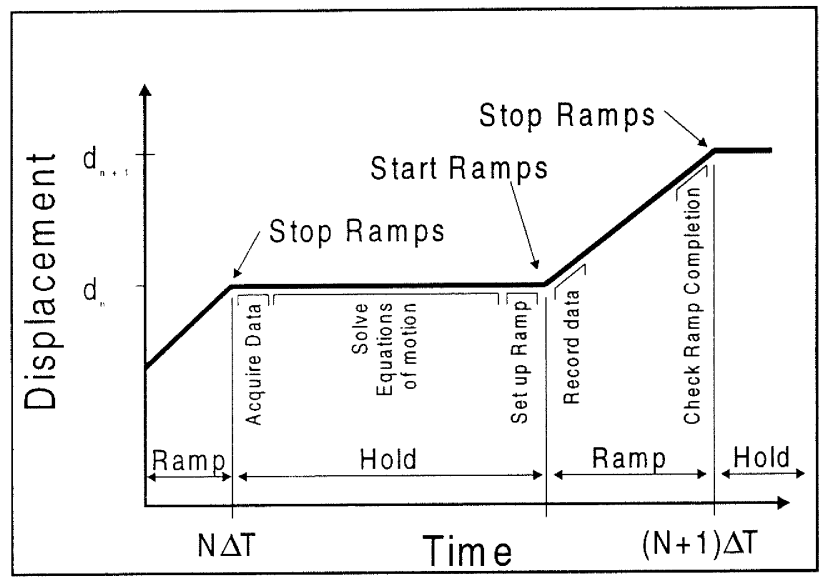

Figure 9: $\quad$ Tasks performed in each step of a pseudo-dynamic test [24].

Recent advances in computing and data acquisition speed have significantly reduced the time required for the hold but the specimen is still subjected to acceleration pulses at the beginning and end of each ramp. In real-time tests, relaxation and acceleration pulse errors are expected to be less significant than those introduced by actuator response delays.

\subsection{Improving the Accuracy}

In a pseudo-dynamic test, the dynamic forces are balanced using Equation 5 at the end of each time step. It is difficult to obtain an accurate measurement of the specimen stiffness because it needs to be calculated from two force measurements that are both likely to be affected by relaxation. Better accuracy can be obtained by using the measured force, $R_{M}$ [25] in place of the stiffness term, $K d$, in Equation 5. This method needs further modification for use with a multiple degree-of-freedom test though.
Further improvement can be obtained in a multiple degreesof-freedom test by replacing the viscous damping, $\mathrm{Cv}$, in Equation 5 with dissipation (i.e., damping) within the integration scheme (e.g. [25]). Dissipation removes the artificial coupling between vibration modes which can cause the higher frequency modes to distort the more useful lower frequency modes [26] but at the cost of being controlled by less obvious parameters within the solution algorithm. It is also desirable because constant viscous damping can produce 'unexpected results' in non-linear tests. Thewalt and Mahin [25] attributed these problems to the damping which, because it is based on the mass and initial specimen stiffness, remained high when the specimen degrades and the stiffness reduces. This problem could be more significant in timber because the stiffness is more consistently lower than it is in other materials (e.g., with steel, the stiffness only reduces for the short periods that it is 'yielding'). 
A useful method of providing a controlled amount of numerical dissipation was developed by Hilber, Hughs and Taylor [27]. Their algorithm, derived from Newmark's algorithm, consists of a series of equations which are solved to give $d, v$ and a at discrete times or steps during the course of the test. For a single degree-of-freedom system, the algorithm has the following set of equations [25]:

$$
\begin{aligned}
& \mathrm{Ma}_{\mathrm{i}+1}+\mathrm{Cv}_{\mathrm{i}+1}+(1+\alpha) \mathrm{R}_{\mathrm{M}, \mathrm{i}+1}-\alpha \mathrm{R}_{\mathrm{M}, \mathrm{i}}=\mathrm{F}_{\mathrm{i}+1} \\
& \mathrm{~d}_{\mathrm{i}+1}=\mathrm{d}_{\mathrm{i}}+\left[\mathrm{v}_{\mathrm{i}}+\left((0.5-\beta) \mathrm{a}_{\mathrm{i}}-\beta \mathrm{a}_{\mathrm{i}+1}\right) \Delta \mathrm{t}\right] \Delta \mathrm{t} \\
& \mathrm{v}_{\mathrm{i}+1}=\mathrm{v}_{\mathrm{i}}+\left((1-\gamma) \mathrm{a}_{\mathrm{i}}-\gamma \mathrm{a}_{\mathrm{i}+1}\right) \Delta \mathrm{t}
\end{aligned}
$$

where the i subscripts denote the time at step i $\Delta t$ and $\alpha, \beta$ and $\gamma$ are the integration parameters. Stability and desirable

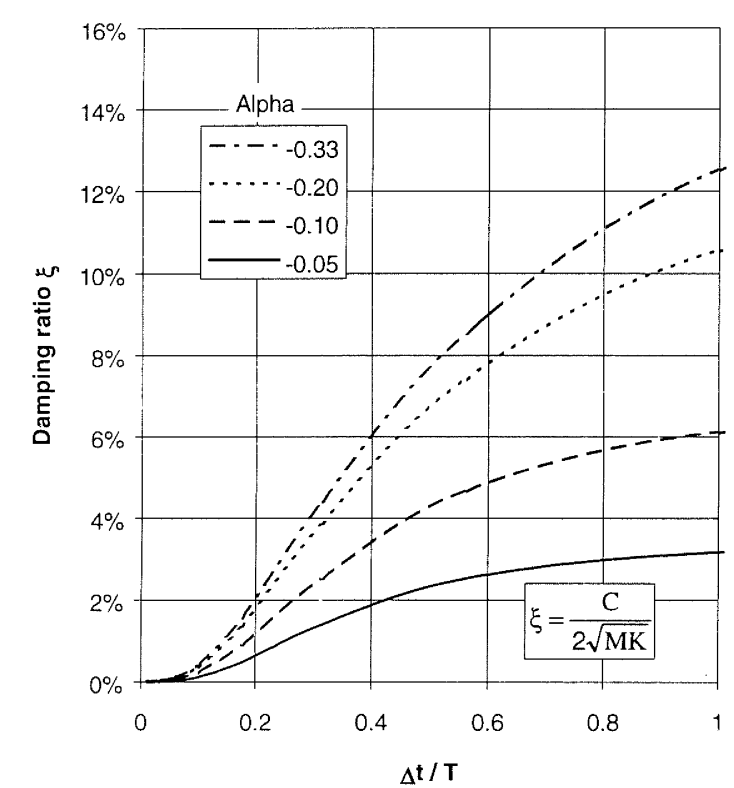

dissipation properties are achieved by setting $\beta$ and $\gamma$ to the following functions of $\alpha$ :

$$
\begin{aligned}
& \beta=(1-\alpha)^{2} / 4 \\
& \gamma=0.5-\alpha
\end{aligned}
$$

The useful range of $\alpha$ is from $-1 / 3$ to 0 with $\alpha=0$ giving Newmark's trapezoidal rule (with no dissipation). The damping and period errors both increase as the time step, $\Delta \mathrm{t}$, increases relative to the natural period, $\mathrm{T}$, as shown in Figure 10 [27]. Figure 10 also shows that the period error (i.e. [ $\mathrm{T}$ apparent period]/T) can be quite considerable when the time step approaches the natural period.

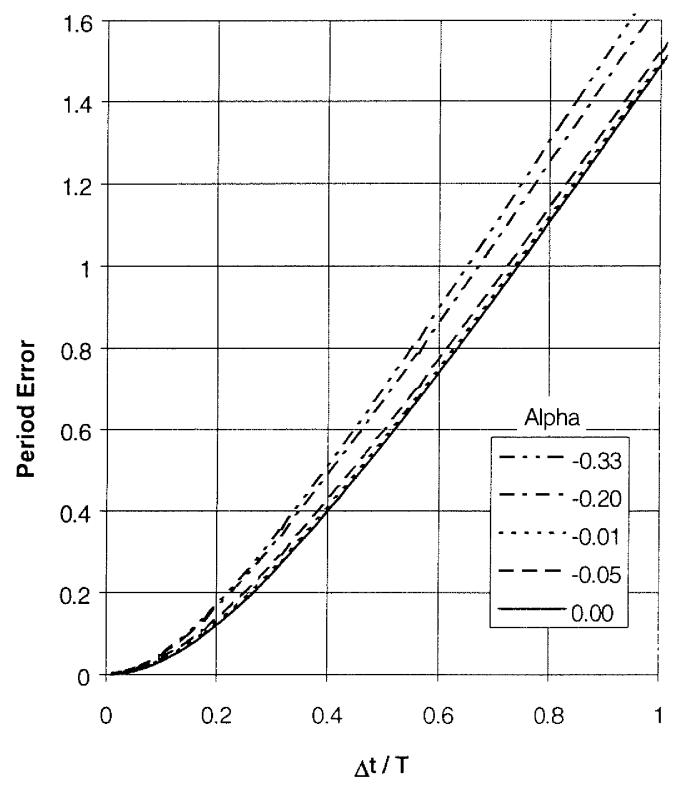

Figure 10: $\quad$ Damping and period error as a function of time step, natural period and $\alpha$ [27].

The analysis system (Figure 7b) adopted by most experimenters calculates the target displacement for the end of the step using the force acquired at the beginning of the step. This can make Equation 5 unbalanced at the end of the step when the specimen stiffness changes during the step. The unbalance is normally corrected in the subsequent step but the error may accumulate when this occurs over a large number of steps.

Thewalt and Mahin [25] used the force measured during the ramp (Figure 9) to modify the applied displacement, correcting it for non-linear specimen behaviour while the ramp is in progress. To do this (Figure 11), they separated the algorithm used to solve Equation 5 into implicit and explicit components. The explicit component was calculated once at the beginning of the ramp and held constant throughout the ramp. The actuator command displacement was then continuously updated during the ramp using an analog computer to add the explicit component to the implicit component derived from the measured force. 


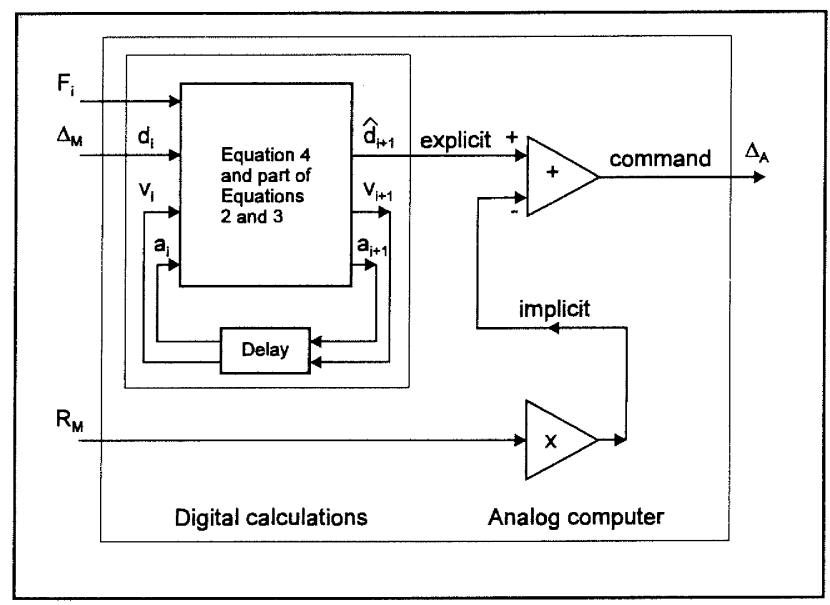

Figure 11: Thewalt and Mahin's analysis system [25].

\subsection{Continuous Testing}

A continuous analysis system (Figure $7 b$ ) was developed at BRANZ for components or assemblages susceptible to relaxation. This uses an analog computer to eliminate relaxation during the hold phase of the traditional ramp and hold method (Figure 9).

Two forms were proposed for the BRANZ controller (Figure 12). In the first, Figure 12a, the integration is performed by the analogue computer to give continuous control over the acceleration, velocity and displacement of each actuator. This form was recently found to be similar to the design used for the first (1974) pseudo-dynamic tests [22]. A mixed controller was proposed (Figure 12b), with additional numerical error correction, for tests using numerical dissipation. This was never implemented because there was little difference between the analogue and numerical methods for a single degree-of-freedom test as will be shown later.

The information flow for the analogue controller is given in Figure 12a for one of two actuators (or axes). The controller for the second actuator is identical. An analogue adder, labelled A1, is used to continuously 'calculate' the acceleration using a rearrangement of the Equation 5. For convenience, Equation 5 is divided by the mass so that acceleration is balanced rather than the force. This allows an earthquake acceleration to be used directly.

The summed acceleration is integrated twice using I1 and $\mathrm{I} 2$ to obtain the velocity and displacement respectively. Multiplier M1 converts the measured force to acceleration. Multipliers M2 and M3 return the damping forces from the two actuators into adder A1. (Multiplier M3 is not required for a single axis test.) Adder A2 is used to adjust the measured displacement, $\Delta_{\mathrm{M}}$, equal to the displacement command signal, d. In practice, Adder A2 will often be within the servo-controller that is used to operate the actuator.

The analogue controller is well suited to conducting real-time tests because only an earthquake acceleration record is required as input and there is almost no delay required for the integration. The system is also less susceptible to data acquisition errors and processing delays because the computer is only used to generate the acceleration signal and acquire the responses during the test.

The analogue controller is less suitable for real-time or multiple degree-of-freedom tests because:

- the damping is directly coupled between actuators and is not able to be replaced by the more desirable numerical dissipation used to damp out unwanted high frequency responses;

- the specimen is not able to be tested as part of a structure because the remainder of the structure can not be modelled easily; and

- there is no means of compensating for servo-controller lag (response delays) which introduce 'negative damping' into the test.

- A large number of multipliers are required to transform the forces, accelerations, velocities and displacements to and from their decoupled states. This is much simpler using a digital controller. 


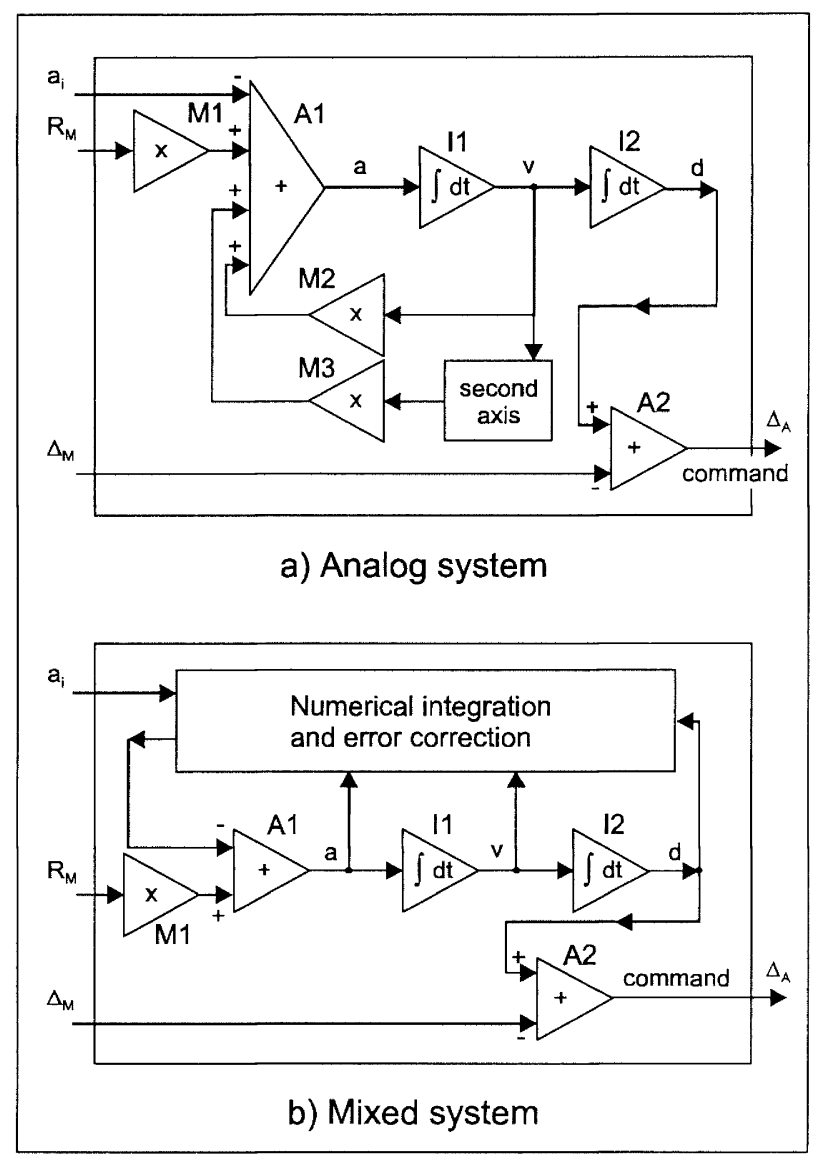

Figure 12: BRANZ continuous analysis systems

\subsection{Implementation}

An analogue controller (Figure 12a) was designed and built using integrated circuit amplifiers for both adders and integrators. The complete system was built on an $8 \mathrm{~cm}$ square circuit board that plugs directly into a PC-based data acquisition card. The acceleration, force, velocity, command displacement and specimen displacement are recorded by the data acquisition card and stored on disk for further processing. A waveform generator in the data acquisition card is used to feed the earthquake acceleration record into the controller. The controller and data acquisition are controlled by software written using the Visual Basic programming language.

The analogue controller is calibrated before each use to compensate for temperature drift within the electronics and to verify that it is operating correctly. An acceleration pulse is used to check that the mass and damping are set correctly and an earthquake acceleration record is used to check that accelerations, velocities and displacements are within the range of the acquisition system.

A perfectly elastic specimen is simulated for the calibration, with the force input connected directly to the displacement command output. The displacement response acquired during the calibration (eg. Figure 13a) is compared with a numerically integrated response. The integrator is then adjusted (M1 in Figure 12a adjusts the mass and M2 adjusts the ratio of damping to mass) until the amplitude and decay of the acquired and calculated responses match visually. The calibration is then checked using the earthquake record (eg Figure 13b). Both acquired responses are normally within 1 percent of the numerically integrated responses and have not therefore been included in Figure 13. 

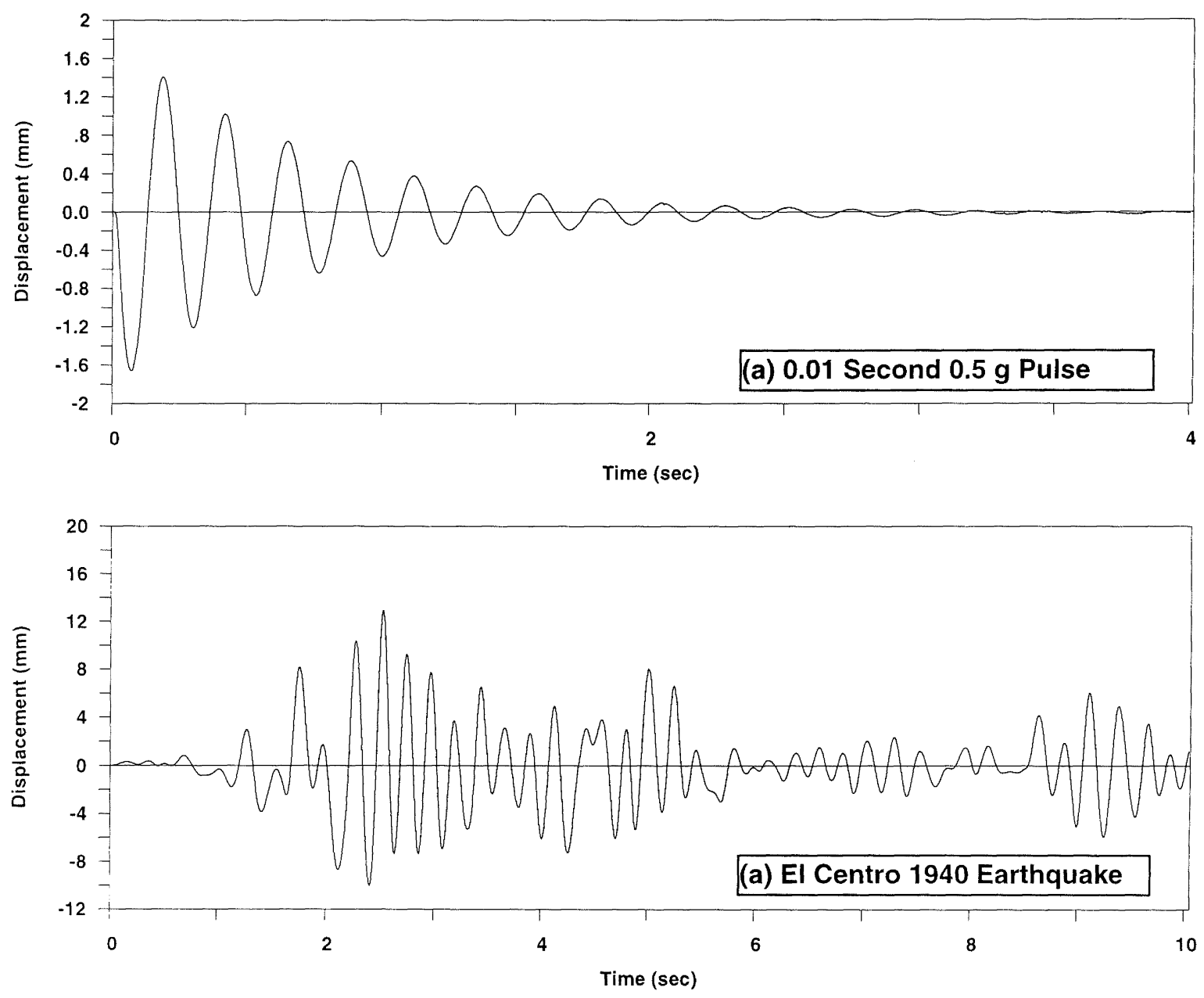

Figure 13: Displacement responses during calibration for a 5 tonne mass, a simulated stiffness of $1.84 \mathrm{kN} / \mathrm{mm}$ and $5 \%$ of critical damping.

Servo-controller delays were expected to affect the accuracy of the test. To examine this, a second check was conducted with the actuator displacement used in place of the specimen load. The response (Figure 14) indicated that the greatest delay was approximately 0.02 second, which was considered to be insignificant. (The test was conducted at $1 / 20$ real-time. For a real-time test, the corresponding delay of $0.4 \mathrm{sec}$ would be unacceptably large.) The analogue controller performed considerably better than was anticipated during its development. The Figure 13 and 14 responses indicate that the controller produces a very accurate simulation of a shaketable test on an elastic, single degree-of-freedom specimen. It is expected that the same accuracy can be achieved when testing a real, degrading specimen.
The analogue controller was set to $1 / 20$ real time, which introduces an approximation into the test because of creep. Tests of nailed timber joints [28] indicated that the ultimate strength increase could be approximated by a straight line when the strength ratio and test time are both plotted on logarithmic scales (Figure 15). (Where "static" strength was considered to be at a rate of $2 \mathrm{~mm} /$ minute.) This suggests that the ultimate strength measured in a $1 / 20$-scaled time test of a timber specimen needs to be multiplied by 1.11 to convert it to an ultimate strength for a real time test. This relationship needs to be confirmed both for full size bracing specimens and for parts of the load-deformation response other than the ultimate strength. It also suggests that the pseudo-dynamic test may produce higher measured strengths than quasi-static reverse-cyclic tests. 

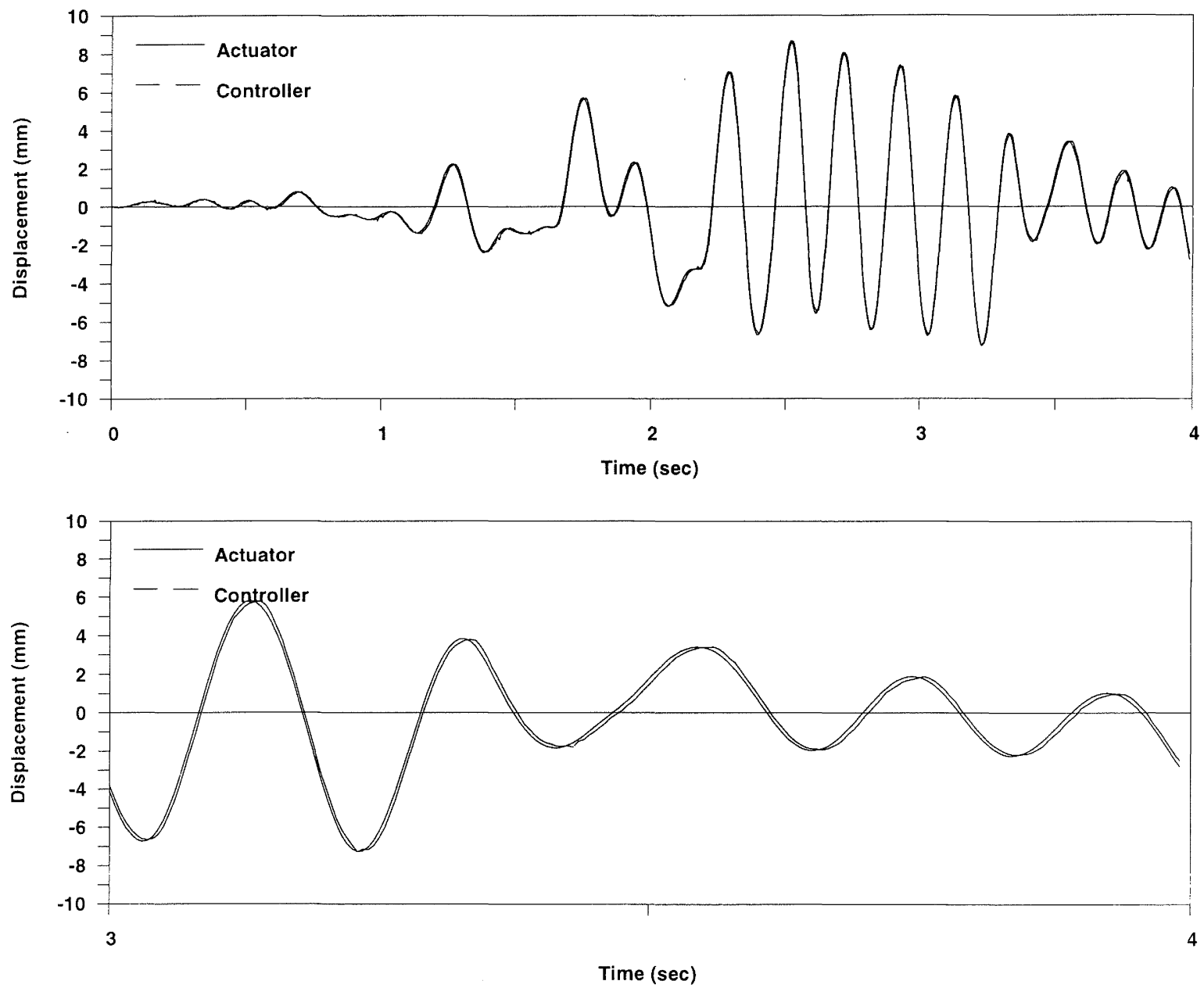

Figure 14: Displacement responses of the simulated specimen (actuator) and displacement command

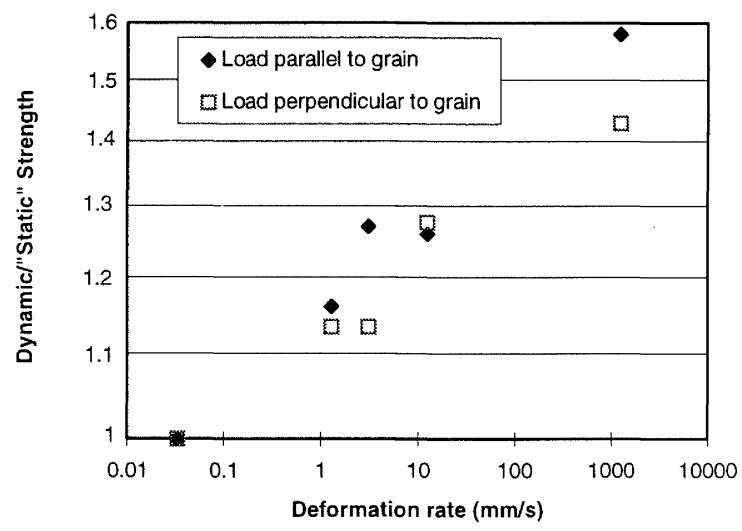

Figure 15: $\quad$ Ultimate strengths of nailed timber joints for varying loading rates [29]. 


\section{MODEL VERIFICATION BY PSEUDO-DYNAMIC TESTING}

Pseudodynamic tests were conducted on three full scale 6.4 $m$ long timber framed bracing wall specimens to assess the proposed rating system and the BRANZ analytical model. One wall was typical of internal wall construction and the other two of exterior wall construction (Figure 16). The internal wall specimen had two internal doorways, a segment

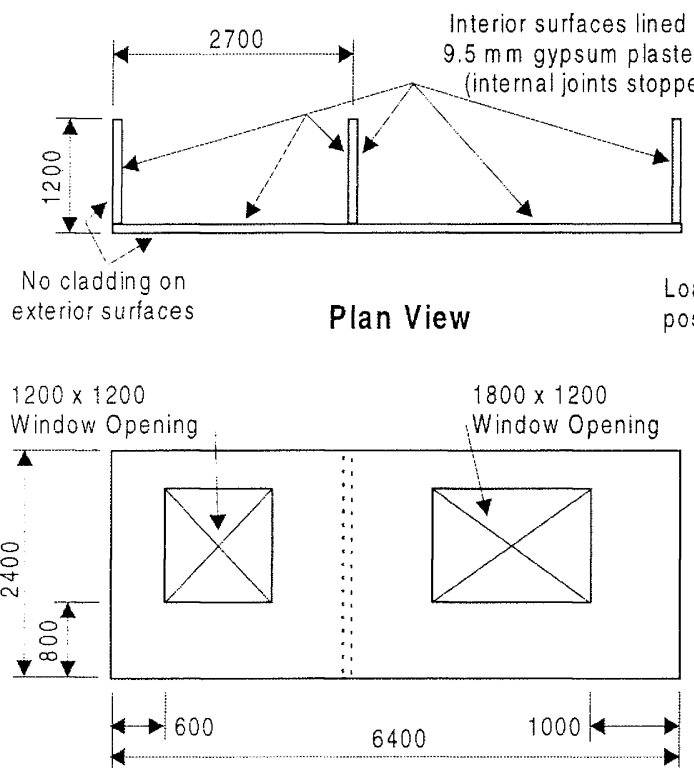

Elevation of exterior wall at one end and segments of interior walls at the other end and adjacent to the central doorway. The exterior wall specimens each had two window openings, exterior wall segments at each end and an interior wall segment. The test specimens were identical to those tested by Thurston [29] except the internal wall had additional metal straps attaching the door trimmer studs to the foundation beam to make the wall strength in the weak direction similar to its strength in its strong direction.
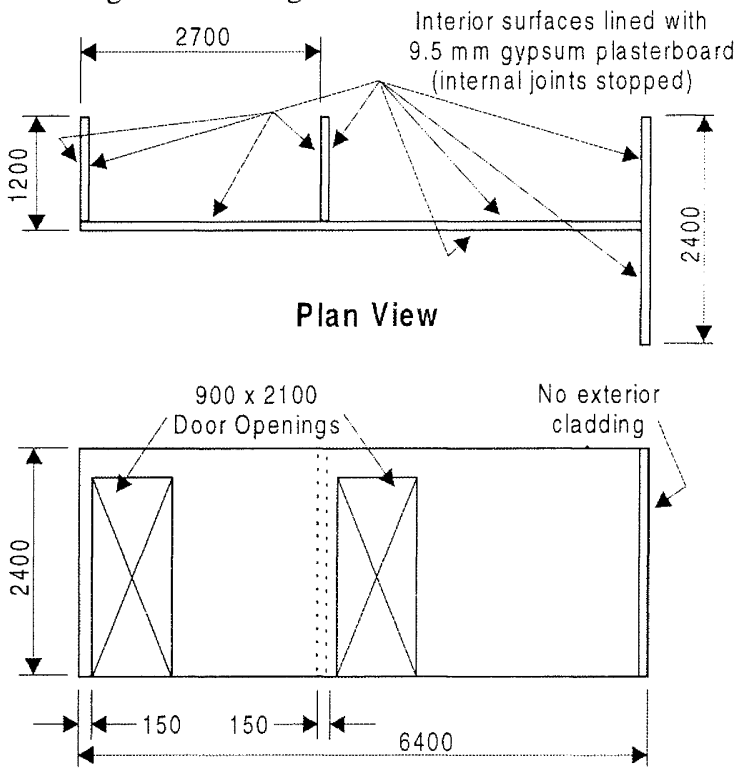

Elevation

\section{External Wall Test Specimen}

\section{Internal Wall Test Specimen}

Figure 16: $\quad$ External and internal wall specimen construction details [29].

An early version [13] of the BraceRate software was used to assess the seismic masses that the test specimens were capable of restraining. This matched Dean's bar-and-spring [12] model to the test specimen responses reported by
Thurston (Figure 17) [29]. The mass was then assessed at a displacement of $16 \mathrm{~mm}$ (Table 1) using two earthquake records.

Table 1 Specimen Ratings based on reverse cyclic tests

\begin{tabular}{|c|c|c|c|c|}
\hline Specimen & $\begin{array}{l}\text { Ultimate } \\
\text { Strength } \\
\text { (kN) }\end{array}$ & $\begin{array}{c}\text { Initial } \\
\text { Stiffness } \\
\text { (kN/mm) }\end{array}$ & Earthquake Record & $\begin{array}{c}\text { Rated } \\
\text { Mass } \\
(\mathrm{kg})\end{array}$ \\
\hline Interior & 27 & 5.7 & $1.25 \times$ El-Centro 1940 & 5000 \\
\hline Exterior & 14 & 3.0 & $\begin{array}{c}1.25 \times \text { El-Centro } 1940 \\
\text { NZS } 4203 \text { Matahina }\end{array}$ & $\begin{array}{l}3500 \\
3500\end{array}$ \\
\hline
\end{tabular}



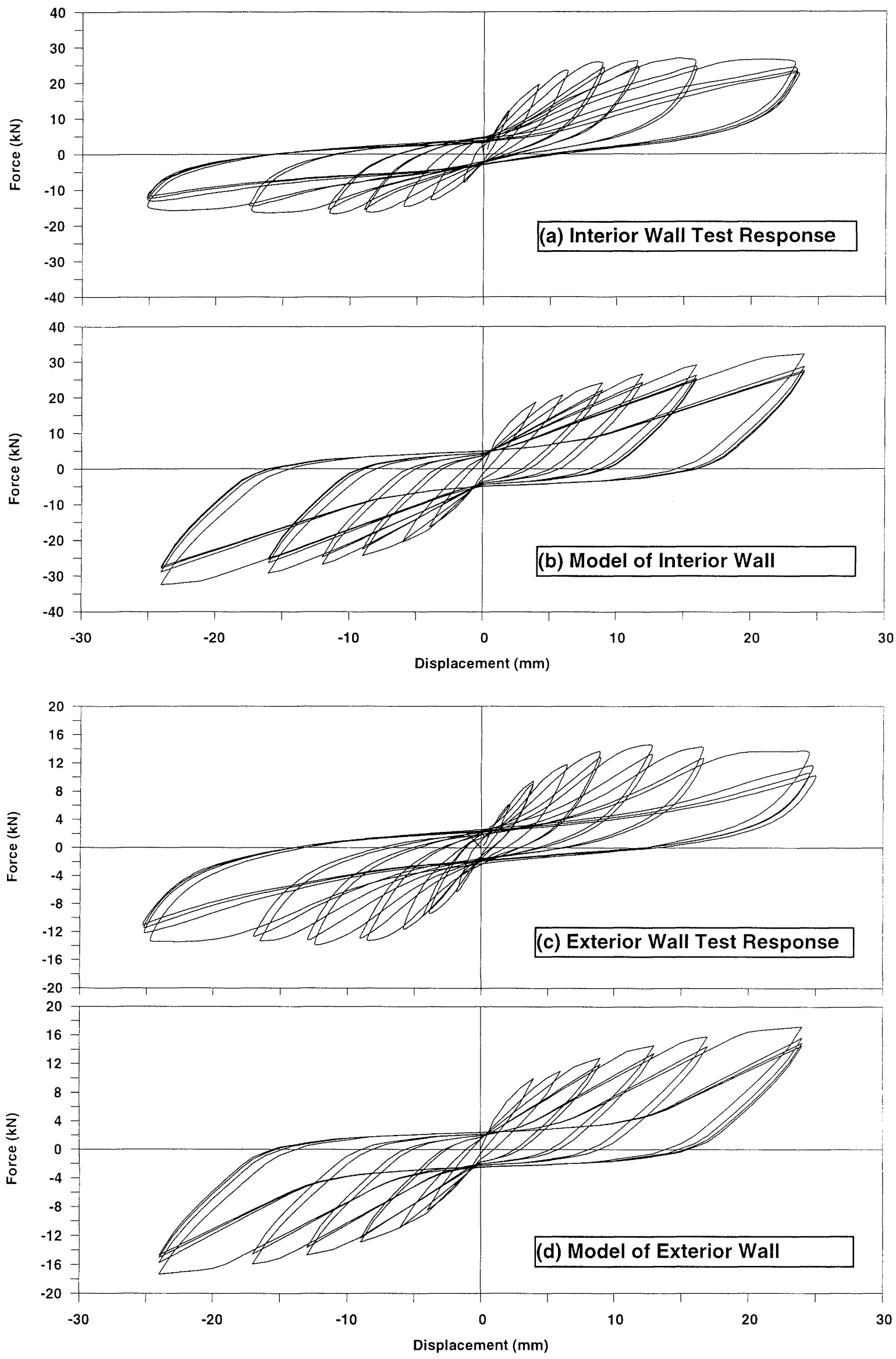

Figure 17: Comparison of test specimen responses [29] and BRANZ analytical model. 
The BRANZ analytical model was matched to the cyclic test specimen responses using the BraceRate software. The analytical model matched the cyclic response of the interior wall reasonably accurately up to $16 \mathrm{~mm}$ displacement (Figure 17) but was unable to match the exterior wall response for negative displacements or beyond $8 \mathrm{~mm}$ positive displacement.

The interior wall specimen was tested pseudo-dynamically with a simulated mass of $5000 \mathrm{~kg}$. A load-displacement plot for the test is given in Figure 18.
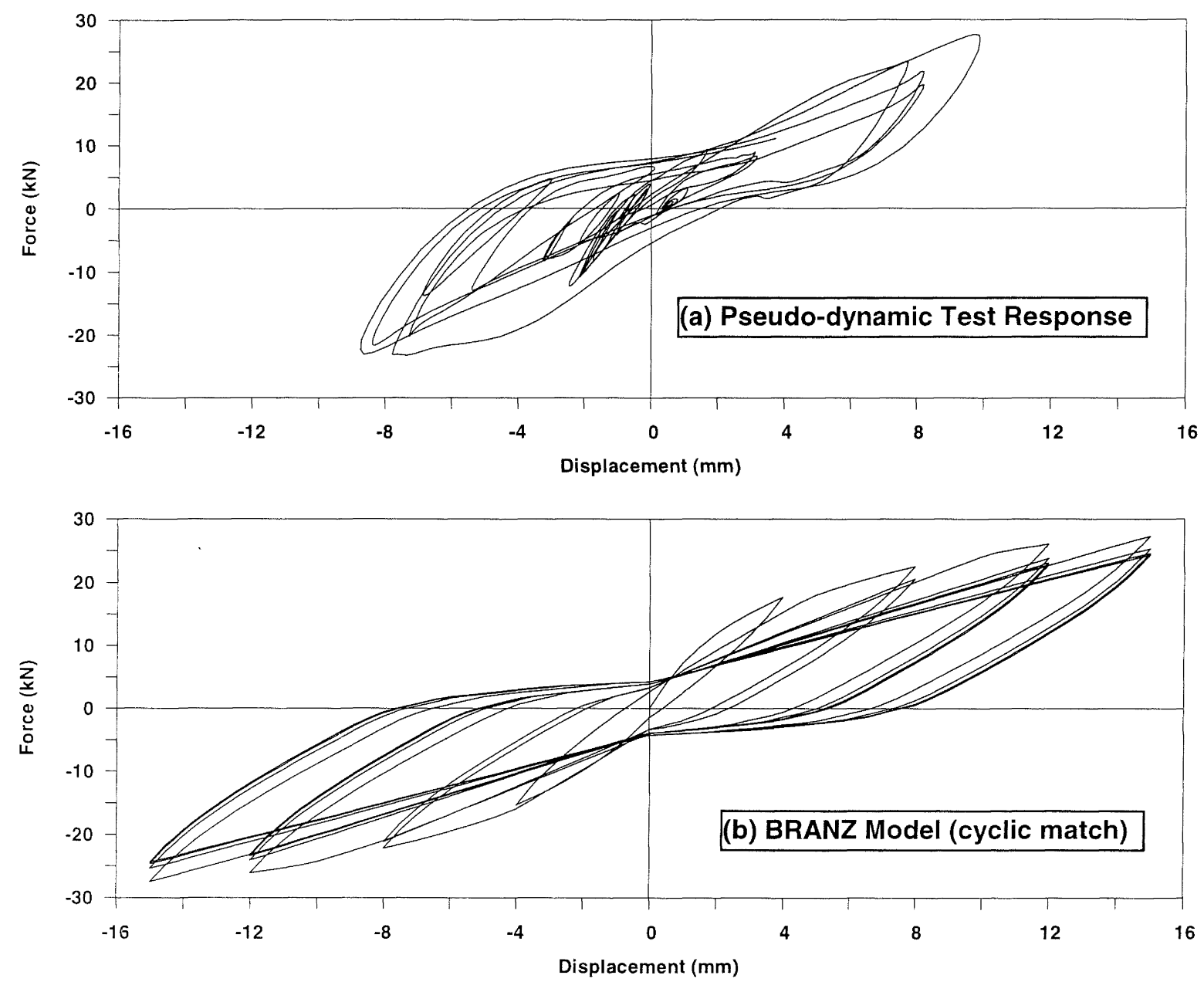

Figure 18: $\quad$ Comparison of Interior wall pseudo-dynamic test response and BRANZ analytical model.

The displacement-time response of the pseudo-dynamic test specimen was very closely matched by a time-history analysis using the BRANZ model as shown in Figure 19. The pseudodynamic test displacement-time responses for the exterior wall specimens were well modelled by the Figure $17 \mathrm{~d}$ model as shown in Figures 20 to 22. (Where the specimen had already been tested, the model was cycled to the same displacement limits as the test specimen before the time- history analysis started.) The pseudo-dynamic test was stopped after about 5 seconds for exterior wall 1 (Figure 20) when the specimen moved beyond an equipment limit. The maximum displacement of the test specimen was recorded as $28 \mathrm{~mm}$ (at 5.2 seconds). This coincided with the time at which the maximum displacement was predicted by the BRANZ model. 

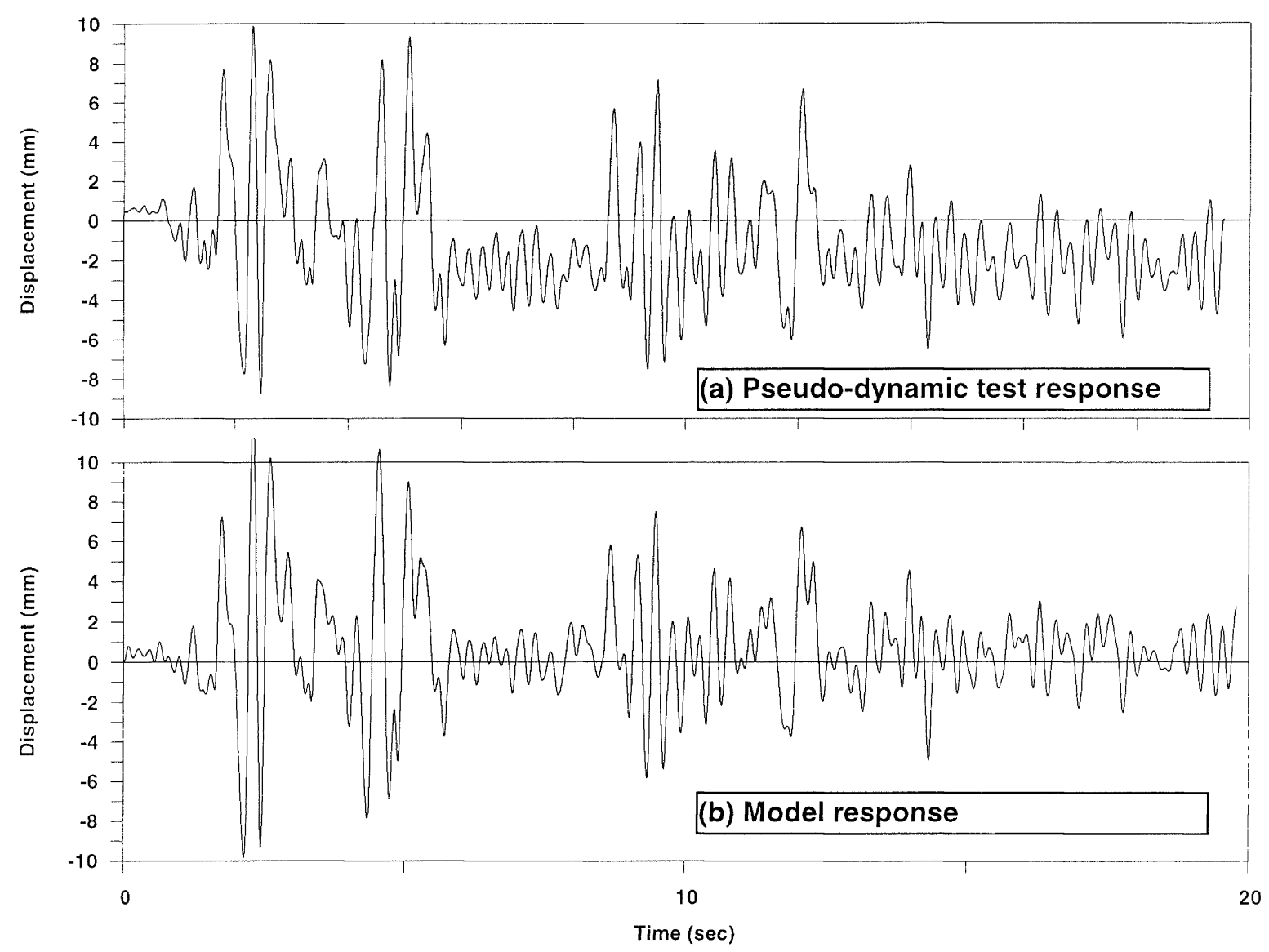

Figure 19: $\quad$ Interior wall responses with a mass of $5000 \mathrm{~kg}$ and subjected to $1.25 \times$ El-Centro 1940 earthquake record (3.8 $\%$ damping).

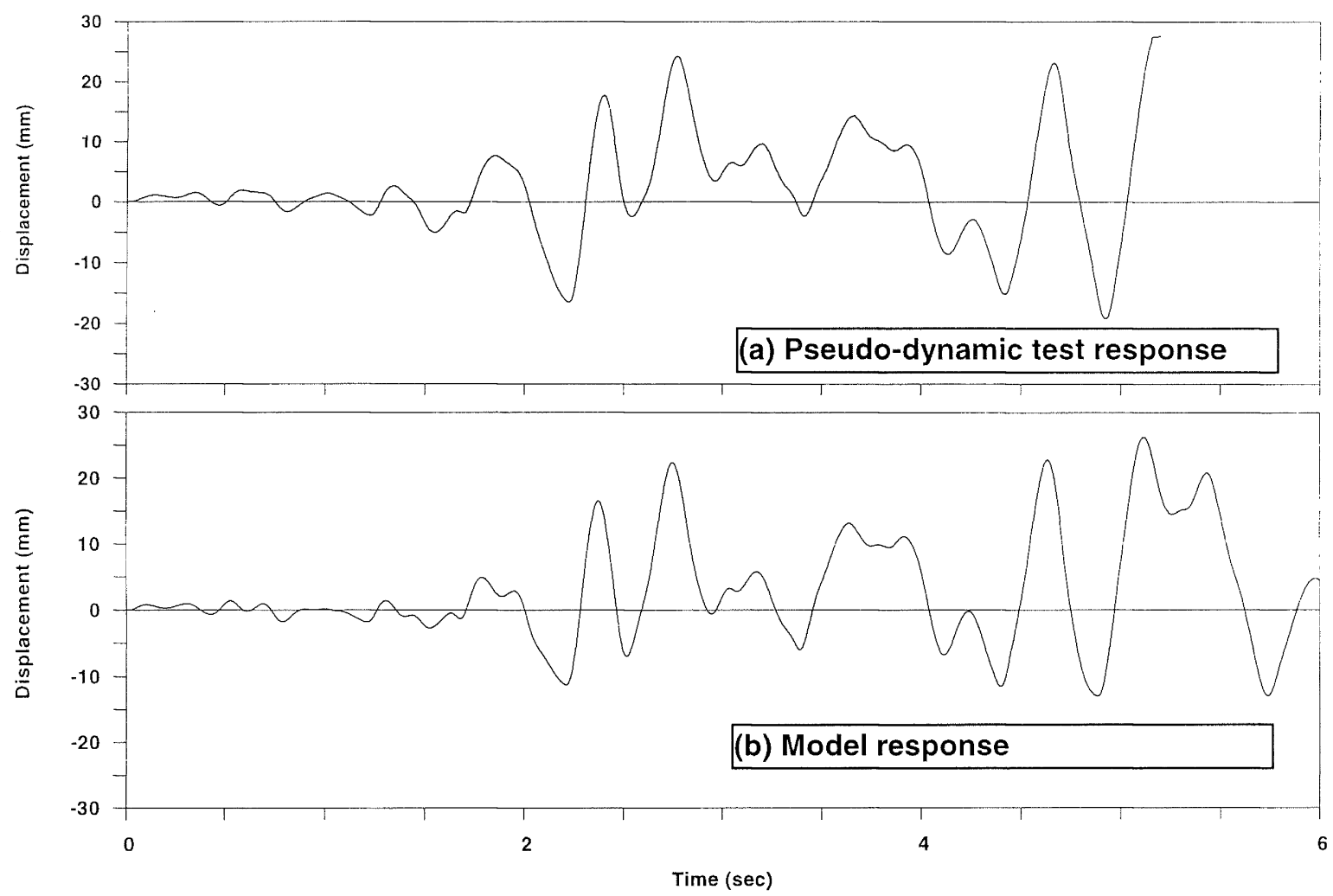

Figure 20: $\quad$ Exterior wall 1 responses with a mass of $3500 \mathrm{~kg}$ and subjected to the El-Centro 1940 earthquake record modified to match the NZS 4203 elastic response spectrum (4.9\% viscous damping). 


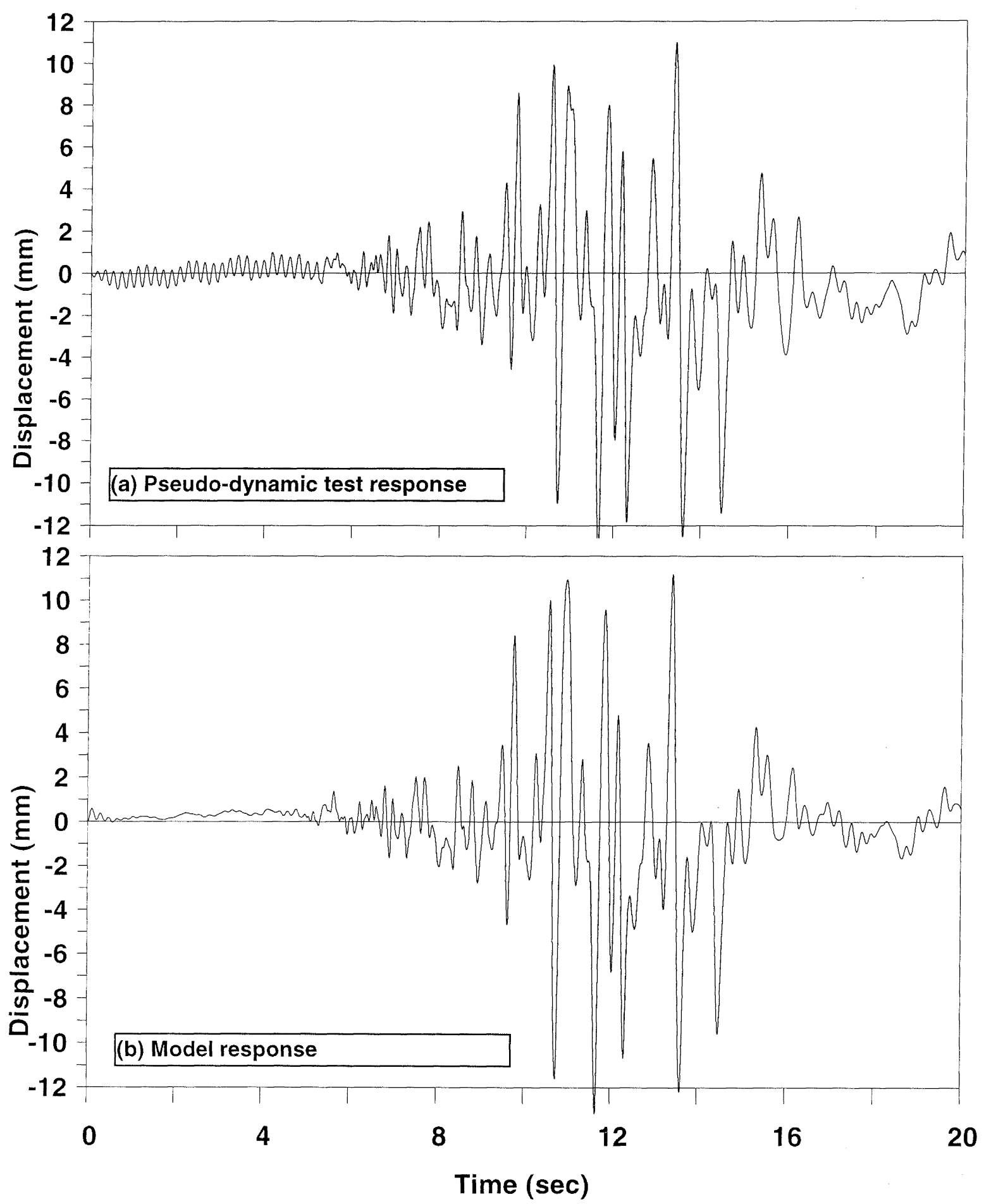

Figure 21: $\quad$ Exterior wall 2 responses with a mass of $3500 \mathrm{~kg}$ and subjected to the Matahina earthquake record modified to match the NZS 4203 elastic response spectrum (4.9\% viscous damping). 

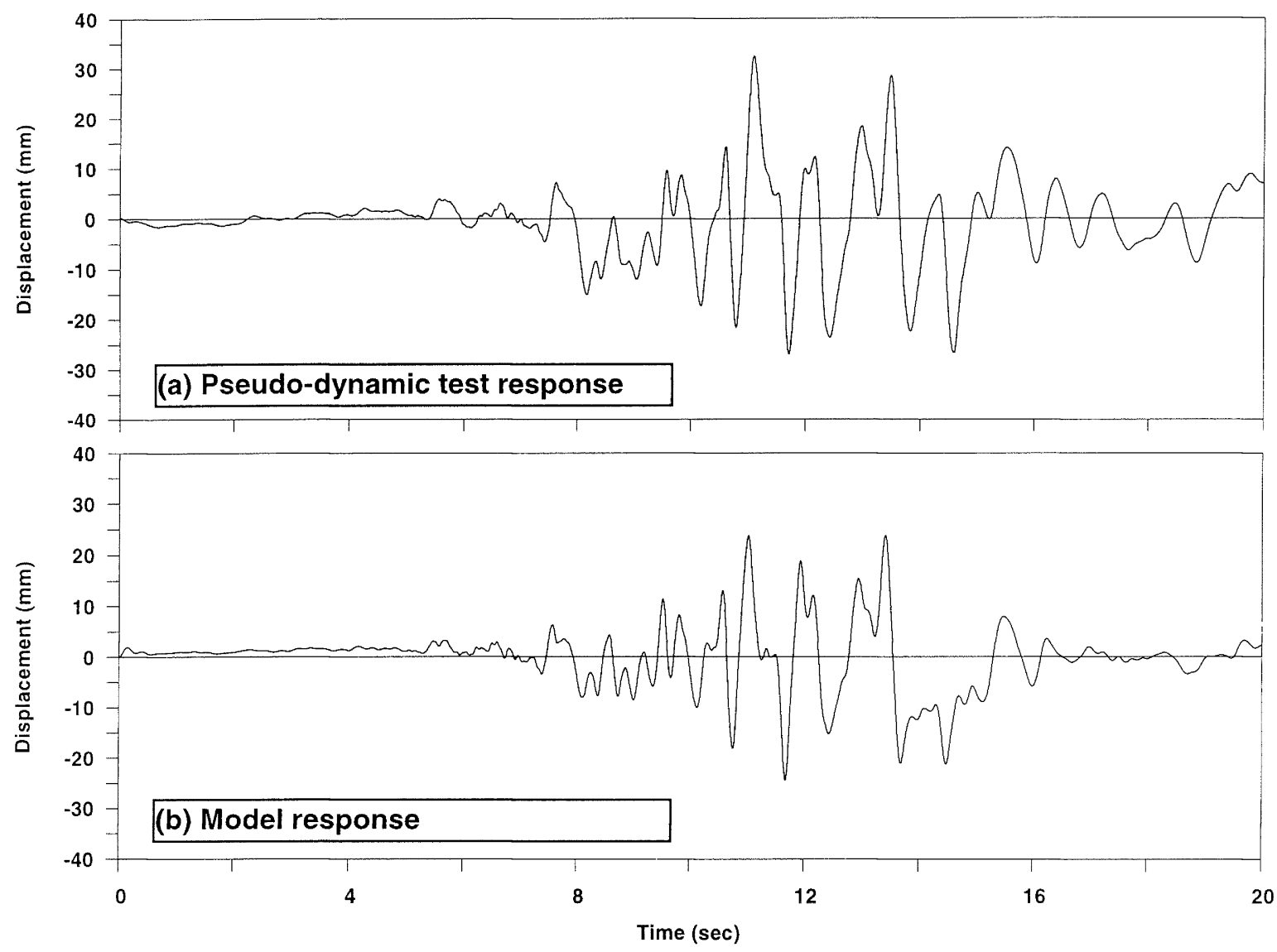

Figure 22: $\quad$ Exterior wall 2 (second test) responses with a mass of $3500 \mathrm{~kg}$ and subjected to $1.25 \times$ the Matahina earthquake record modified to match the NZS 4203 elastic response spectrum (4.9\% viscous damping).

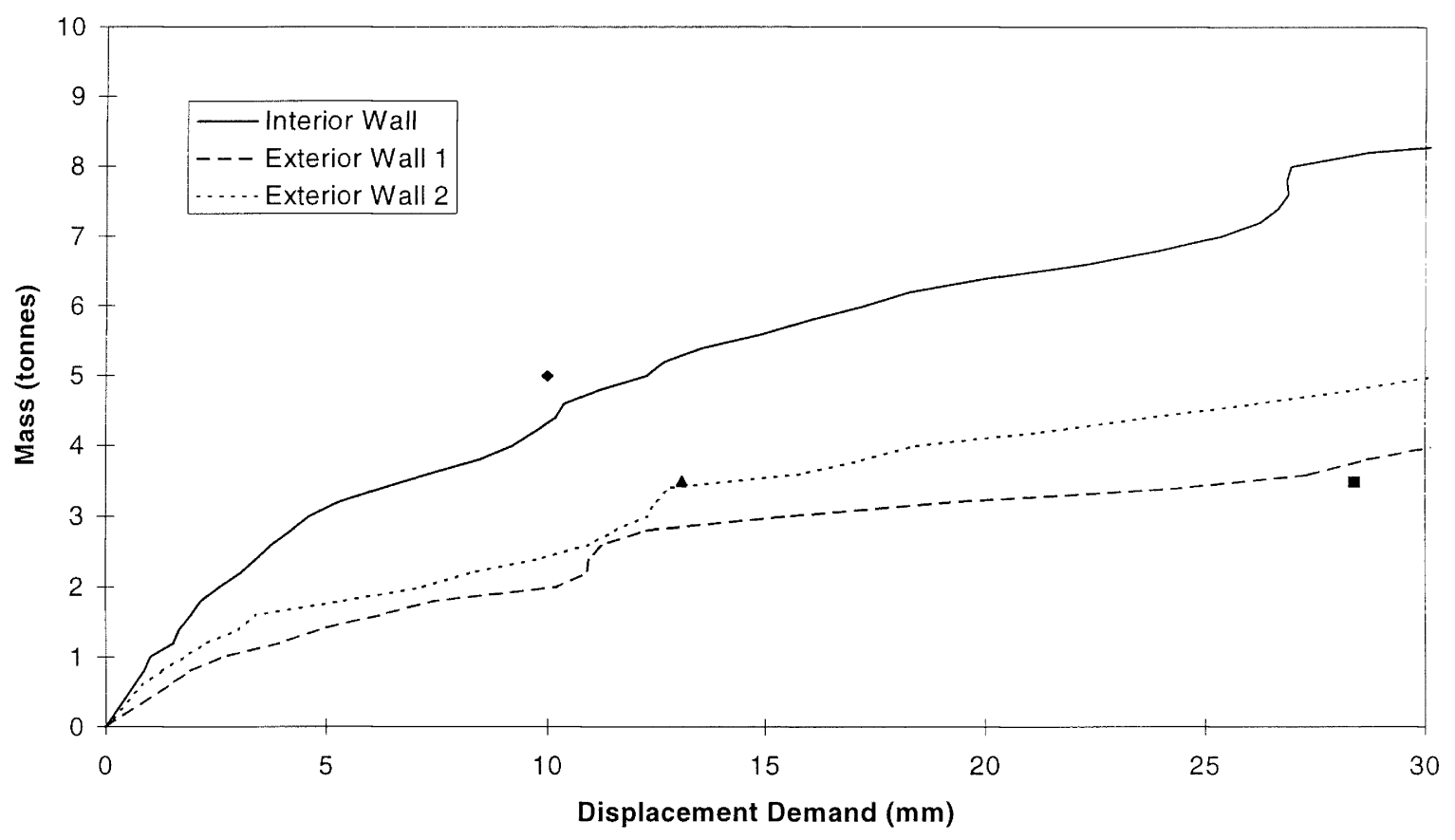

Figure 23: $\quad$ Mass-displacement demand plots for the three walls. 
The excellent agreement between the pseudo-dynamic test specimen responses (shown as points) and the massdisplacement responses predicted by the BRANZ model is illustrated in Figure 23

\section{COMPARISON WITH CURRENT P21 EVALUATION PROCEDURE}

The newly developed rating method was used to check the ratings assigned by the current $\mathrm{P} 21$ evaluation procedure [4] described in Section 2. To do this, the mass that gypsum plasterboard lined test walls are capable of restraining was evaluated using BraceRate. The mass able to be restrained by the two specimens is plotted in Figure 24 for the five earthquakes and for displacement demands of up to $30 \mathrm{~mm}$. The equivalent rating in Bracing Units is indicated on the right axis. This was calculated from the mass using Equation 4 (ie for a building with $\mathrm{T}=0.4$ seconds, a specimen ductility of $\mu=4$ and "intermediate" soil).

The ratings, evaluated using the current $(1979,1990)$ P21 evaluation procedure at the $16 \mathrm{~mm}$ displacement cycles (approximately the maximum reliable displacement), are shown as points in Figure 24. These ratings are almost twice those evaluated using the new method

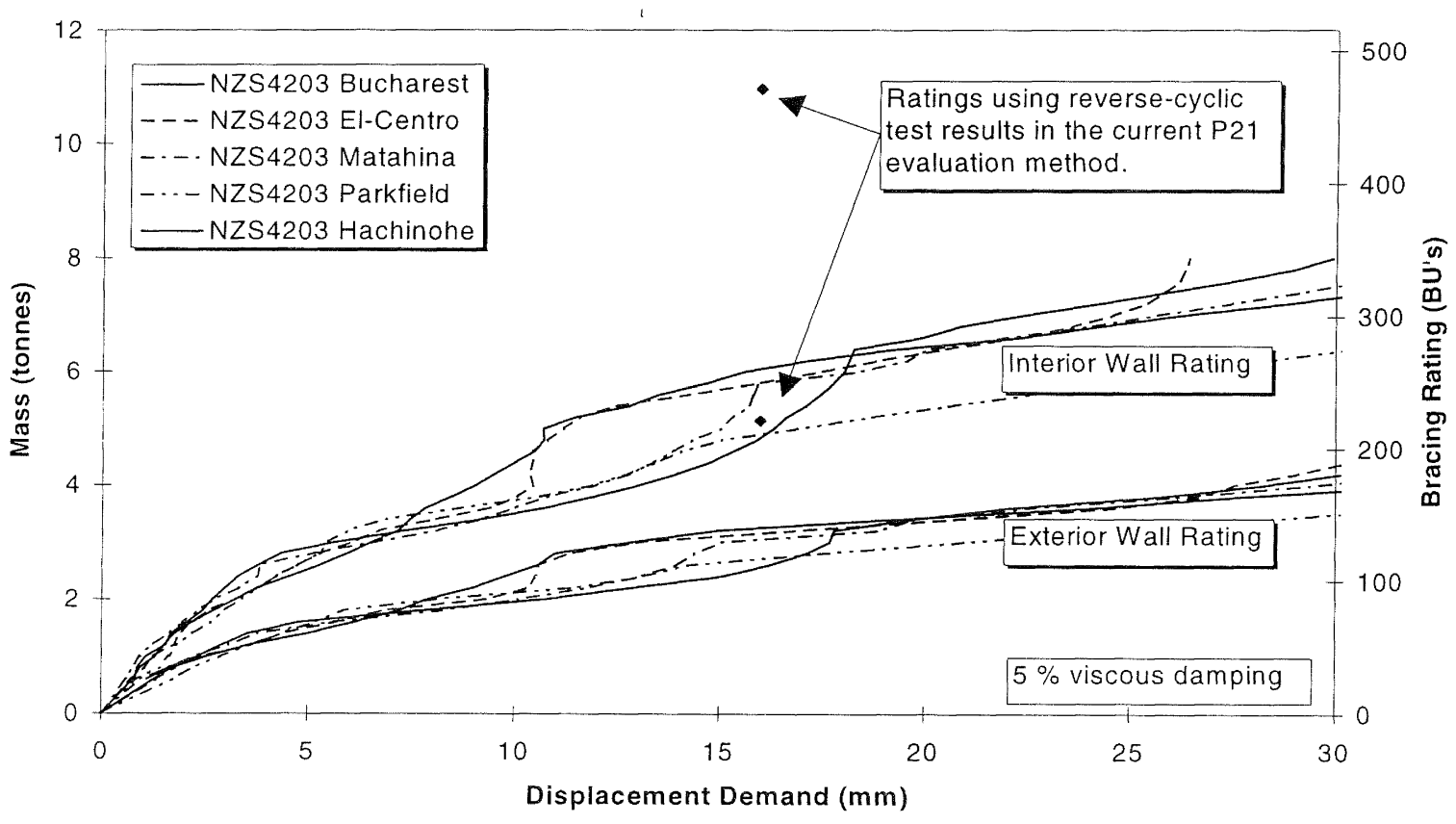

Figure 24: $\quad$ Mass-Displacement ratings for NZS 3604 Zone A.

This significant differences between the ratings obtained using the proposed and current methods occur because:

1. The current rating method assumes a natural building period of 0.4 seconds, which imposes displacements of about $32 \mathrm{~mm}$ upon an elastically responding building. Most bracing elements used in NZS 3604 style buildings have maximum reliable displacements that are smaller 32 $\mathrm{mm}$ and their resistance has dropped to a fraction of the maximum at that displacement. The incompatibility is accentuated when the response is inelastic because the displacement demand will normally be greater than 32 $\mathrm{mm}$.

2. The proposed method rates the specimen at a "maximum reliable displacement" rather than the maximum test displacement. This may be unnecessarily conservative but the reserve displacement capacity needed to provide lifesafety protection during a "maximum credible earthquake" is not currently quantified in the Loadings Standard, NZS 4203. (This is likely to be provided by the definition of available ductility, $\mu_{\mathrm{a}}=\Sigma \mu / 8$, proposed by Park for concrete and steel structures [8].)
3. The viscous damping used with the proposed method (5 percent of critical, based on the initial stiffness) may be insufficient to account for damping provided by the additional "non-structural" walls that are not specifically detailed as or counted as bracing elements. Thirty percent of critical damping is required to restrain the mass predicted using the existing rating procedure. It is unlikely that the non-structural walls in a normal building will provide this amount of damping though.

4. The Figure 24 comparison rated the whole wall as a single bracing element. Where the full height segments of the walls provide bracing, the bracing ratings for the exterior and interior walls reduce to 90 and 275 Bracing Units respectively (using the ratings published in the manufacturer's literature). These are closer to the ratings calculated using the new method but this reflects the greater restraint and therefore strength provided by the return walls rather than "damping" provided by additional walls.

5. The current method assumes a structural ductility factor of $\mu=4$. The method of calculating this based upon a "yield" displacement at half of the peak load is open to question. 
The differences clearly need to be addressed to prevent the construction of unsafe buildings. Both the load and the resistance sides of the design procedure need to be modified to address the effects noted above. The loading side is difficult to modify because the values are tabulated within the standard, NZS 3604:1999, which has only recently been revised. (The natural period of the building was decreased as part of the revision.) The resistance side is more readily modified but will affect the ratings published by a number of bracing system manufacturers. It is also desirable that the ratings retain the same simple relationship between bracing units and force that will still be used for wind design.

The whole rating method is currently being investigated at BRANZ but worthwhile improvements can be made by revising the definition of yield in order to provide better correlation between the current evaluation method and the results obtained using the proposed method. This form of modification would simplify the re-evaluation of existing test results and allows it to be used with the inelastic NZS 4203 spectra with their implicit elasto-plastic "ductility".

The current definition of $\mu=y^{+} / d$ (Figure 25) was originally "... adopted as an interim measure while further investigation is continuing ..." [4]. An elasto-plastic "yield" strength of $\mathrm{P} / 2$ may have been more appropriate than R for use with the NZS 4203 elasto-plastic response spectra. This was probably rejected because the residual strength, $R$, is always greater than $\mathrm{P} / 2$ and would produce excessively conservative ratings. It would, however, have eliminated the peculiar assignment of a ductility of $\mu=2$ that the current method applies to elastically responding test specimens.

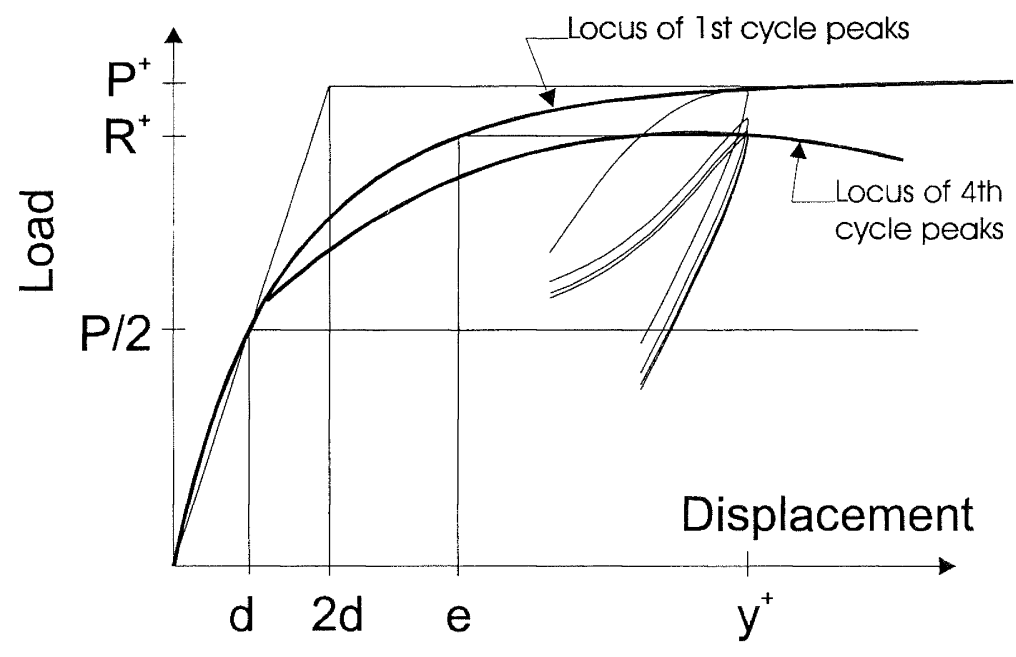

Figure 25: Definitions of yield for use with the current ' $P 21$ ' rating procedure

The ductility could be reduced to $\mu=y^{+} / 2 d$ or $\mu=y^{+} / e$ (Figure 25) without significantly increasing the complexity of re-evaluating ratings for existing bracing systems. Bracing ratings were recalculated using these two methods for the two plasterboard-lined walls described previously. Ratings calculated using the three methods are compared with the average Figure 24 time-history ratings (ie, the average rating for the 5 earthquakes) in the following table:

Table 2 Bracing Ratings from the different evaluation methods

\begin{tabular}{c|cccc} 
Wall & $\mu=\mathbf{y}^{+} / \mathbf{d}$ & $\mu=\mathbf{y}^{+} / 2 \mathbf{d}$ & $\mu=\mathbf{y}^{+} / \mathbf{e}$ & Time-History \\
\hline Interior & 470 & 445 & 327 & 250 \\
Exterior & 220 & 210 & 160 & 130
\end{tabular}

The ratings calculated for $\mu=y^{+} / e$ are reduced to only 25 to 30 percent higher than those produced by time-history analysis. This more modest difference is more likely to represent the strength difference between that of an isolated test element and the same element attached to and strengthened by its surrounding walls.

Comparisons need to be undertaken for a range of bracing materials and systems because plasterboard is generally stiffer but weaker than wood- and cement- based lining materials.

\section{CONCLUSIONS}

A new method of rating the resistance of bracing elements has been proposed for use with NZS 3604. A new analytical model has been developed which accurately models the loaddisplacement responses of these degrading bracing elements. Computer software has been developed which fits the analytical model to reverse-cyclic test results and evaluates a seismic bracing rating for the elements. A continuous pseudo-dynamic test method has been developed and used to verify the analytical model. The time-displacement responses 
of pseudo-dynamic tests on three plasterboard lined timberframed wall specimens were accurately predicted by the analytical model.

The current P21 rating procedure was shown to produce ratings that are less conservative than the new method. A simple modification to the current method was proposed and shown to give better agreement with the analytical and pseudo-dynamic ratings. The modification still needs to be verified for a wider range of specimens.

\section{ACKNOWLEDGMENTS}

This research reported herein was funded by the New Zealand Building Research Levy and the Foundation for Research, Science and Technology from the Public Good Science Fund. Materials for the tests were generously supplied by Winstone Wallboards, Carter Holt Harvey Timber and Fletcher Challenge Forests. Their use does not represent their endorsement nor does it imply that they are better or worse than any other products. The author also wishes to thank BRANZ colleagues Andrew King and Stuart Thurston for discussion and reviews of this paper.

\section{REFERENCES}

I Standards New Zealand (SNZ) (1990). "Code of Practice for Light Timber Framed Buildings not Requiring Specific Design", Standards New Zealand, NZS 3604, Wellington.

2 Herbert, P.D. \& King A.B. (1998). "Racking Resistance of Bracing Walls in Low-rise Buildings Subject to Earthquake Attack". Building Research Association of New Zealand, Study Report 78. Judgeford.

3 Cooney, R.C. and Collins, M.J. (1979), (revised 1982, 1987, 1988). "A wall bracing test and evaluation procedure". Building Research Association of New Zealand, Technical Paper P21. Judgeford.

4 King, A.B. and Lim, K.Y. (1991). "An Evaluation Method of P21 Test Results For Use With NZS 3604:1990", Building Research Association of New Zealand, Technical Recommendation No 10, Judgeford.

5 Deam, B.L. and King, A.B. (1996). "Pseudo-dynamic seismic testing of structural timber elements". Proceedings, International Wood Engineering Conference, New Orleans, Lousiana, 1: 53-59.

6 King A.B. \& Deam B.L. (1998). "A Rational Engineering Basis for Assessing Timber Framed Bracing Panels under Earthquake Attack". Proc. Australasian Structural Engineering Conference, Auckland, New Zealand. 2: 949-955.

7 Dean, J.A.. Stewart, W.G. and Carr, A.J. (1987). "The Seismic Design of Plywood Sheathed Timber Frame Shearwalls". Pacific Conference on Earthquake Engineering, Wairakei, New Zealand. 2: 165-175.

8 Park, R. (1989). "Evaluation of Ductility of Structures and Structural Assemblages from Laboratory Testing". Bulletin New Zealand National Society for Earthquake Engineering 22(3): 155-166.
9 Dean, J.A., Stewart, W.G. and Carr, A.J. (1986). "The Seismic Behaviour of Plywood Sheathed Shearwalls". Bulletin New Zealand National Society for Earthquake Engineering 19(1): 48-63.

10 Stewart, W.G. (1987). "The Seismic Design of Plywood Sheathed Shearwalls". Thesis submitted in partial fulfilment of $\mathrm{PhD}$ Degree, University of Canterbury, Christchurch, New Zealand.

11 Foliente, G.C. (1997). "Modelling and Analysis of Timber Structures Under Seismic Loads: State-of-theArt". In Foliente, G.C. (ed) Earthquake Performance and Safety of Timber Structures, Forest Products Society, Madison, Wisconsin.

12 Dean, J.A. (1994). Personal communication

13 Deam, B.L. (1997). "Seismic Ratings for Residential Timber Buildings". BRANZ Study Report 73, Judgeford.

14 Filippou, F.C., Bertero, V.V. and Popov, E.P. (1983). "Effects of bond deterioration on hysteretic behaviour of reinforced concrete joints". EERC Report No. 83-19, University of California, Berkeley.

15 Standards New Zealand (SNZ) (1992). "Code of Practice for General Structural Design and Design Loadings for Buildings", Standards New Zealand, NZS 4203, Wellington.

16 Clow, K., Davidson, B. and Matthews, J. (1995). "A methodology for calculating the optimal bilinear seismic isolation system". New Zealand National Society for Earthquake Engineering Annual Conference, Rotorua. p 15.

17 Clough, R.W. and Penzien, J. (1975). Dynamics of Structures. McGraw-Hill. New York.

18 Thurston, S.J. (1994). "Field Testing of House Pile Foundations Under Lateral Loading". Building Research Association of New Zealand. Study Report SR58. Judgeford

19 Paulay, T. (2000). "Understanding Torsional Phenomena in Ductile Systems". Bulletin New Zealand Society for Earthquake Engineering 33(4): 403-420.

20 Folz, B. and Filiatrault, A. (2001). "Cyclic Analysis of Wood Shear Walls". Journal of Structural Engineering. 127(4): 349-472

21 Kamiya, F. (1988). "Nonlinear earthquake response analysis of sheathed wood walls by a computer-actuator on-line system". In: Proceedings, 1988 International Conference on Timber Engineering; September 19-22; Seattle, Washington. 838-847

22 Takanashi, K. et al. (1974). "Seismic failure analysis of structures by computer pulsator on-line system". In: Journal of the Institute of Industrial Science, University of Tokyo. 26(11): 13-25 (in Japanese).

23 Seible, F.; Hegemier, G.A.; Priestley, M.J.N. (1991). "Full-scale testing of structural masonry systems under simulated seismic loads". In: Proceedings, Pacific Conference on Earthquake Engineering, 20-23 November, Auckland, New Zealand. 2: 197-208 
24 Mahin, S.A.; Shing, P.B. (1985). "Pseudodynamic method for seismic testing". Journal of Structural Engineering 111(7): 1482-1503.

25 Thewalt, C.R. and Mahin, S. A. (1995). "An Unconditionally Stable Hybrid Pseudodynamic Algorithm". Earthquake Engineering and Structural Dynamics. 24(5): 723-731.

26 Nakashima, M.; Kato, H. (1987). "Experimental error growth behaviour and error control in on-line computer test control method". Research Paper No.123. Building Research Institute, Ministry of Construction, Japan.

27 Hilber, H.M.; Hughes, T.J.R.; Taylor, R.L. (1977). "Improved numerical dissipation for time integration schemes in structural dynamics". Earthquake Engineering and Structural Dynamics. 5(3): 283-292.

28 Girhammar, U.A. and Andersson, H. (1988). "Effect of Loading Rate on Nailed Timber Joint Capacity". Journal of Structural Engineering. 114(11): 2439-2456.

29 Thurston, S.J. (1993). "Report on Racking Resistance of Long Sheathed Timber Framed Walls With Openings", Building Research Association of New Zealand, Study Report 54, Judgeford. 